\title{
Incumbency advantage and political campaign spending limits
}

\author{
Ivan Pastine ${ }^{\mathrm{a}}$, Tuvana Pastine ${ }^{\mathrm{b}, *}$ \\ a University College Dublin, Ireland \\ ${ }^{\mathrm{b}}$ National University of Ireland Maynooth, Ireland
}

\section{A R T I C L E I N F O}

\section{Article history:}

Received 31 July 2010

Received in revised form 13 June 2011

Accepted 6 July 2011

Available online 23 July 2011

JEL classification:

D72

Keywords:

Campaign finance legislation

Spending cap

Expenditure limit

Preferential treatment all-pay auction

Contest

Head-start advantage

\begin{abstract}
A B S T R A C T
This paper presents a model which captures the three main arguments for and against campaign spending limits. Campaign spending limits are purported to restrict the incumbent's ability to exploit his fundraising advantage. In contrast to conventional wisdom, a ceiling increases the incumbent's probability of victory regardless of the candidates' relative fundraising abilities as long as the challenger is not more effective in campaign spending. If the challenger is more effective in campaign spending, ceilings have a non-monotonic effect when the incumbent enjoys a mild initial voter disposition advantage; A moderate ceiling decreases the incumbent's probability of victory but further restricting the limit favors the incumbent. Irrespective of incumbency status, the marginal benefit to quality decreases with a more restrictive cap. In an open-seat contest, a more restrictive limit improves the electoral prospects of the superior quality candidate. Stricter ceilings may lead to the unintended consequence of increased expected spending.
\end{abstract}

(c) 2011 Elsevier B.V. All rights reserved.

\section{Introduction}

Many modern democracies have political campaign spending limits. Walecki (2007) finds that out of 60 democracies studied, 25 have caps on political campaign spending including Canada, France, Ireland, Israel, Italy, New Zealand, Spain and the UK. The Corrupt and Illegal Practices Act of 1883 is characterized by historians as a landmark in the development of democracy in England. The main feature of the act is the introduction of limits on the election expenditures permitted in each constituency. The act was expanded in 2000 under the Political Parties, Elections and Referendums Act. In Canada, spending limits for political parties and candidates were first introduced in 1974 and they were re-regulated in 2003. Spending limits now are considered a cornerstone of Canadian democracy. ${ }^{1}$

There is general consensus that the electoral playing field is tilted in favor of the incumbent. In the 2008 US House elections, $94 \%$ of incumbents who chose to run for election were reelected. The average reelection rate in US House election cycles from 1964 to 2008 was $93 \%$. The figure for the US Senate was $81 \%$ for the same time period. Moreover, overwhelming empirical evidence indicates that incumbency gives an advantage in the

\footnotetext{
* Corresponding author at: Department of Economics, NUI Maynooth, County Kildare, Ireland. Tel.: + 3531 7086421; fax: + 35317083934 .

E-mail addresses: Ivan.Pastine@ucd.ie (I. Pastine), Tuvana.Pastine@nuim.ie (T. Pastine).

${ }^{1}$ See Seymour (1970) for discussion on England and Walecki (2007) on Canada.
}

electoral contest. $^{2}$ Political scientists have identified various channels through which incumbency advantage may have deleterious effects on social welfare. The office-holder may be less responsive to his constituents, since he would have little reason to fear defeat. Even if the challenger is of higher quality, he may have a smaller probability of victory than the incumbent. High-quality candidates with high opportunity cost may be deterred from running for office because of weak electoral prospects. The incumbent may not be challenged in the first place decreasing the choices available to constituents.

Proponents of spending limits suggest that ceilings enhance robust competition in the marketplace of ideas by allowing less established candidates to be heard on an equal footing with the established incumbents. However, others argue that incumbents would not have legislated spending caps if limits did not serve them. ${ }^{3}$ In order to assess the impact of ceilings on competitive balance, we analyze whether the challengers' electoral prospects improve with a campaign spending limit in line with the stated intention of campaign spending legislation.

Proponents and opponents of political campaign spending limits base their arguments on one of three sources of asymmetry between the incumbents and challengers; initial voter disposition advantage, efficiency in fundraising and effectiveness in campaign spending.

\footnotetext{
${ }^{2}$ Incumbency advantage is one of the most frequently studied issues in congressional elections research, see Gelman and King (1990).

${ }^{3}$ See Evens (2007) and Bender (1988) in the Canadian and U.S. context for some indirect support for the argument.
} 
Opponents of spending limits point to the importance of initial voter disposition advantage. For example in his dissenting opinion in McConnell v. FEC (2003), ${ }^{4}$ Supreme Court Justice Scalia writes: "If all electioneering were evenhandedly prohibited, incumbents would have an enormous advantage. Likewise, if incumbents and challengers are limited to the same quantity of electioneering, incumbents are favored. In other words, any restriction upon a type of campaign speech that is equally available to challengers and incumbents tends to favor incumbents."

The main argument in favor of spending limits focuses on incumbents' higher efficiency in fundraising. In the US Supreme court case McConnell v. FEC (2003), Justice Stevens argues that "[I] ncumbents have pre-existing relationships with corporations and unions, and groups that wish to procure legislative benefits may tend to support the candidate who, as a sitting officeholder, is already in a position to dispense benefits and is statistically likely to retain office. ... So we do not have a solid theoretical basis for condemning [limits]... as a front for incumbent self-protection." Limits are purported to limit incumbent's ability to exploit this fundraising advantage.

It is also argued that spending limits affect the balance of the electoral competition due to candidates' asymmetric effectiveness in campaign spending. Incumbents are already known by the electorate, whereas challengers often need to campaign just to establish name recognition, providing an additional benefit to campaigning. There is extensive empirical evidence demonstrating that challengers are more effective in turning campaign spending into votes. ${ }^{5}$ Given that challengers are more effective in campaign spending, Samuels (2001) argues that spending limits harm challengers. Surprisingly, we find the opposite: Spending limits can benefit challengers only if they are more effective at campaign spending.

The theoretical literature focuses on these three sources of asymmetry between incumbents and challengers in isolation. In Sahuguet and Perisco (2006) candidates differ only in initial voter disposition and the spending limit is an impediment to the underdog's ability to overcome his initial disadvantage. Meirowitz (2008) has results on the effect of a spending limit for the case where candidates are asymmetric in fundraising efficiency but are symmetric in all other dimensions. The challenger, who has lower fundraising efficiency benefits from spending limits if voters casts their ballots in favor of the challenger when indifferent. In this paper we adapt the electoral contest model of Meirowitz (2008) to examine spending limits where all three sources of asymmetry may coexist. We find that allowing for more than one source of asymmetry leads to significant changes in the predictions of the model.

Limits are intended to level the playing field in favor of the candidate with lesser resources. However if the challenger does not have greater effectiveness of campaign spending, we find that this premise does not hold as long as the incumbent has any initial voterdisposition advantage, however small. The limit always increases the equilibrium probability of victory and the expected payoff of the incumbent with the initial voter disposition advantage irrespective of his relative fundraising efficiency. The challenger must spend more than the incumbent to overcome the incumbent's head-start advantage. Since the maximum the challenger can spend is given by the limit, the incumbent never needs to spend as much as the limit. This implies that the challenger is effectively constrained by the limit while the incumbent is not.

However, if the challenger can turn campaign spending into votes more effectively, we show that a moderate limit may increase the

\footnotetext{
${ }^{4}$ The 1974 Federal Election Campaign Act provided for ceilings on campaign expenditures in the US Presidential, Senate and House elections. In 1976 however, the US Supreme Court deemed expenditure limits to be unconstitutional (Buckleyv. Valeo).

${ }^{5}$ Among others see Glantz et al. (1976), Jacobson (1978, 1981, 1985, 1990),Welch (1981),Abramowitz (1988) and Green and Krasno $(1988,1990)$.
}

equilibrium probability of victory and the expected payoff of the challenger when the incumbent has a mild initial voter-disposition advantage. The incumbent must spend more to match his rival's effective campaign spending and a mild initial voter disposition advantage does not overwhelm this effect. Hence with moderate limits the incumbent is effectively constrained whereas the challenger is not. Moreover, we find that the effect of a spending ceiling may be non-monotonic; A moderate limit increases the probability of victory and the expected payoff of the challenger, however further restricting the limit benefits the incumbent.

While the main focus of the paper is the impact of spending caps on incumbency advantage, we also provide an analysis of spending limits in an open-seat contest. In our analysis of incumbency advantage, candidates are identical in every respect other than the incumbency status. When studying an open-seat contest however, we let the candidates differ in quality. Assuming that the high-quality candidate enjoys a higher degree of campaign effectiveness, a more restrictive limit increases the win probability of the high-quality candidate. This result holds as long as the high-quality candidate enjoys an initial voter disposition advantage due to his prior accomplishments, however small this advantage may be. The lowquality candidate needs to spend more than the high-quality candidate in order to overcome the rival's higher campaign effectiveness. The limit hinders the ability of the low-quality candidate to do so. The cap improves the probability of victory of the high-quality candidate in an open-seat contest.

We show that irrespective of incumbency status, candidates' marginal benefit to quality goes down with a more restrictive spending cap. The higher the candidate's quality the more effective he is in campaign spending. The spending cap restricts the ability to take advantage of quality. Hence the more restrictive the binding limit can weaken the incentive to invest in quality.

The paper also provides an analysis of the effect of spending limits on expected campaign spending. It is often argued that caps can help restrict campaign spending and reduce fundraising. Fundraising takes time and effort and may distract politicians from their legislative duties. Furthermore greater fundraising may lead to undue policy influence of special interest groups. However, we find that, contrary to one of its intentions, the imposition of stricter limits may lead to fiercer competition and increased spending.

Finally, this paper makes a small but useful contribution to the auction literature. In the electoral contest the winner takes the seat but both players' costs of effort are sunk. Hence the contest takes the form of an all-pay auction where one of the contestants has a headstart advantage (initial voter disposition advantage). In the auction literature terminology, the contestant with the head-start advantage is subject to "preferential treatment". Konrad (2002) is the first paper to characterize the equilibrium of a preferential treatment all-pay auction. ${ }^{6}$ Konrad (2002) is extended by Meirowitz (2008) to allow for asymmetric marginal costs of bidding and by Pastine and Pastine (2010) to analyze the preferential treatment all-pay auction equilibrium with a cap on bids. This current paper analyzes a cap in a preferential treatment all-pay auction where contestants may be asymmetric both in the cost of bidding and in the effectiveness of their bids. This is non-trivial because these asymmetries and the preferential treatment interact in the presence of a cap.

\section{Framework}

We consider a slightly generalized version of Meirowitz (2008). In this model, voters are "impressionable" in the terminology of Grossman and Helpman (1996) so campaign spending is persuasive. Voters have a predisposition toward one candidate which can be

\footnotetext{
${ }^{6}$ Also see Siegel (2010) and Kirkegaard (2010) for all-pay auctions with head-start advantages.
} 
overcome through campaign spending which alters the voters' perceptions. Campaign spending enters the utility function of the voters as in the models of persuasive advertising in consumer product markets by Dixit and Norman (1978) and Becker and Murphy (1993). Campaigning enhances familiarity. The more familiar a voter is with the winning candidate, the higher the utility the voter derives from the election result. Given their preferences the voters make their voting decisions rationally, however the mechanism through which spending is persuasive is left as a black box.

There is considerable evidence demonstrating that the majority of political advertising has little direct informational content. Abrajano and Morton (2004) find that about seventy percent of the political advertisements in the 2000 US Congressional elections did not involve substance. Much of political advertising attempts to create the impression that the candidate is compassionate, honest, competent, friendly, etc. rather than providing hard information about the policy position of the candidates. ${ }^{7}$ In Senate campaigns from 1988 to 1992, Kahn and Kenney (1999) report that only thirty six percent of political advertisements made an issue a major focus. Campaign spending provides indirect information to voters about the valence of the candidate via signaling as in Potters et al. (1997) and Prat (2002a,b). ${ }^{8}$ However, Mueller and Stratmann (1994) argue that television advertising is primarily persuasive and that the growth of television advertising signifies the growth of the relative importance of persuasive campaigning. This paper will not enter the debate on whether the majority of campaign spending is persuasive or informative either directly or indirectly through signaling. But rather it takes the existence of persuasive advertising as given and focuses on its equilibrium implications.

Two candidates indexed by $i \epsilon\{1,2\}$ run for office. Candidates simultaneously choose their campaign spending levels, $a_{i}$. A continuum of voters observes the spending levels and cast their ballots based on their initial disposition toward the candidates and the spending of the two campaigns. The outcome of the election is determined by simple majority. Each voter's initial disposition for Candidate 1 over Candidate 2 is i.i.d. $t_{z} \sim \mathrm{U}\left[-\alpha_{2}, \alpha_{1}\right]$. So if $t_{z}<0$ voter $z$ initially prefers Candidate 2 . After observing the campaign spending of the two candidates the voter's utility is:

$u_{z}= \begin{cases}t_{z}+\eta_{1} a_{1} & \text { if Candidate } 1 \text { wins } \\ \eta_{2} a_{2} & \text { if Candidate } 2 \text { wins }\end{cases}$

where $\eta_{i}>0$ is the campaign spending effectiveness of candidate $i .^{9}$

Voter $z$ casts his vote for Candidate 1 if $t_{z}+\eta_{1} a_{1}>\eta_{2} a_{2}$. If the inequality is reversed he votes for Candidate 2 . If indifferent, he flips a coin. Since $t_{z} \sim \mathrm{U}\left[-\alpha_{2}, \alpha_{1}\right]$, the median voter has $t_{z}=\left(\alpha_{1}-\alpha_{2}\right) / 2 \equiv \alpha$. Label candidates as 1 and 2 such that the majority of voters have an initial predisposition for Candidate $1, \alpha_{1}>\alpha_{2}$ so $\alpha>0$. Candidate 1 wins the election if he can capture the vote of the median voter, i.e. if $\alpha+\eta_{1} a_{1}>\eta_{2} a_{2}$. Hence the parameter $\alpha$ gives the initial voter disposition advantage enjoyed by Candidate 1 . In case of equality, $\alpha+\eta_{1} a_{1}=\eta_{2} a_{2}$, Candidate 1 wins with probability $1 / 2$. We refer to $\alpha+\eta_{1} a_{1}$ as the "score" of Candidate 1 , and $\eta_{2} a_{2}$ as the "score" of Candidate 2. Let $k$ denote the level of the campaign spending ceiling, so a candidate's spending cannot exceed $k$.

\footnotetext{
7 There are well-developed theoretical models of informative political campaign advertising. In Soberman and Sadoulet (2007) campaign advertising provides direct information about the valence of the candidate á la Butters (1977). In Austen-Smith (1987) and Coate (2004) campaign advertising directly informs voters about the policy position of the candidate. Konrad (2004) has an inverse campaign model where candidates inform voters who would lose from the policy proposals of the rival.

${ }^{8}$ Also see Pastine and Pastine (2002) for an additional explanation for why advertising that contains no direct information may influence its target audience.

${ }^{9}$ All that is needed is a median voter model where voters can be influenced by campaign spending and one candidate has a potential head-start advantage. Meirowitz (2008) generates the same game form from a different underlying model.
}

The value of winning the office is the same for both candidates and is normalized to one. The marginal utility cost of raising funds for campaign spending is denoted by $\beta_{i}>0$. Candidates differ in their efficiency of raising funds; the lower $\beta_{i}$, the greater is candidate $i$ 's efficiency of fundraising. If $i$ wins his payoff is $1-\beta_{i} a_{i}$. If his opponent wins candidate $i$ 's payoff is $-\beta_{i} a_{i}$.

For each candidate define $\bar{a}_{i}$ as the highest feasible spending at which his valuation from winning is non-negative:

$\bar{a}_{i}= \begin{cases}1 / \beta_{i} & \text { if } k \geq 1 / \beta_{i} \\ k & \text { if } k<1 / \beta_{i}\end{cases}$

Define a function $M_{i}\left(a_{j}\right)$ that gives the amount candidate $i$ must spend to effectively match the score of his rival when the rival spends $a_{j}$ :

$M_{1}\left(a_{2}\right)=\left(\eta_{2} a_{2}-\alpha\right) / \eta_{1}$
$M_{2}\left(a_{1}\right)=\left(\eta_{1} a_{1}+\alpha\right) / \eta_{2}$

These functions are inverses of each other. Candidate 1 is referred to as the "strong" candidate if $\bar{a}_{1} \geq M_{1}\left(\bar{a}_{2}\right)$, where Candidate 1's maximum feasible spending at which his valuation from winning is non-negative exceeds what he needs to spend to effectively match the score of Candidate 2 if Candidate 2 were to engage in his highest feasible spending at which his valuation from winning is nonnegative. Otherwise Candidate 2 is referred to as the strong candidate. The strong candidate's rival is referred to as the "weak" candidate. Whenever $\bar{a}_{i}>M_{i}\left(\bar{a}_{j}\right)$ candidate $i$ has the option of guaranteeing victory and a positive payoff with spending just above $M_{i}\left(\bar{a}_{j}\right)$.

This framework is a generalization of Meirowitz (2008) where we explicitly included the candidates' degrees of effectiveness of campaign spending. In Meirowitz (2008) without campaign spending restrictions, $\beta$ can capture an aggregate technology of fundraising and campaign spending effectiveness. This is because in Meirowitz (2008) $a_{i}$ takes the interpretation of spending measured in effective units. However spending caps limit the face value of spending, not the effective units. Therefore in our framework $a_{i}$ is the monetary value of campaign spending and the parameters $\beta_{i}$ and $\eta_{i}$ represent two different sources of asymmetry. With spending limits it will be shown that the effects of these two sources of asymmetry are distinctly different from each other.

\section{Equilibrium}

If Candidate 1 's initial voter disposition advantage is severe, $\alpha \geq \eta_{2} / \beta_{2}$, with or without spending limits the unique equilibrium is in pure strategies. Candidate 2 cannot overcome the head-start advantage of the rival, even if Candidate 2 spends $1 / \beta_{2}$ and Candidate 1 spends nothing. Hence neither candidate exerts any effort. Likewise with a sufficiently restrictive spending limit, $k<\alpha / \eta_{2}$, the unique equilibrium is in pure strategies where there is no competition. If $\eta_{2}$ $k<\alpha$, Candidate 2 cannot overcome the voters' initial disposition with spending equal to $k$, even if Candidate 1 exerts no effort. Below we describe the equilibrium for the non-trivial cases where there is competition in equilibrium, i.e. where voter's initial disposition is not too strong, $\alpha<\eta_{2} / \beta_{2}$, and the cap is not too restrictive, $k>\alpha / \eta_{2}$. In the interest of space we ignore the non-generic special case $k=\alpha /\left(\eta_{2}-\right.$ $\left.\eta_{1}\right)$ where $M_{i}(k)=k^{10}$

The victor captures the seat but both candidates' efforts are sunk. Hence the contest has the form of an all-pay auction. With and without a cap, the unique equilibrium is in mixed strategies. If Candidate 1 were to

\footnotetext{
${ }^{10}$ This case is non-generic in the sense that for any given level of $k$, if $\alpha, \eta_{1}$ and/or $\eta_{2}$ are drawn from continuous distributions there is zero probability of the case occurring. Nevertheless it is interesting theoretically. In this non-generic case if both players spend the maximum permitted amount they tie and the contest is decided by lottery. Hence the equilibrium mirrors the equilibrium in Che and Gale (1998) and can be solved using their approach.
} 
spend $a^{\prime}$, the optimal response of Candidate 2 would be to either spend enough to beat the rival's score or to spend zero if that spending yields a negative payoff or is not possible due to the spending cap. In either case $a^{\prime}$ would not be the best response of Candidate 1 .

Let $F_{i}(x) \equiv \operatorname{prob}\left(a_{i} \leq x\right) \forall a_{i} \in[0, \infty)$ denote the cumulative distribution function of candidate $i$ in an arbitrary mixed-strategy equilibrium and let $a_{i}^{\text {sup }}$ denote the supremum of the support of each candidate's equilibrium mixed strategy. Let $\vartheta$ be the larger of the two candidates' $a_{i}^{\text {sup }}$ in the competition without a spending cap. A cap is termed non-binding if $k>\vartheta$. Otherwise the cap is binding. A more restrictive cap refers to a smaller $k$ when the cap is binding.

The two propositions below characterize the equilibrium of the electoral contest. The first proposition describes the equilibrium for parameter values where Candidate 1 is strong, $\bar{a}_{1} \geq M_{1}\left(\bar{a}_{2}\right)$. The second proposition describes the equilibrium for parameter values where Candidate 2 is strong, $\bar{a}_{1}<M_{1}\left(\bar{a}_{2}\right)$. The propositions are preceded by Lemmas 1 and 2 that give the parameter values where Propositions 1 and 2 apply without a binding cap and with a binding cap, respectively.

To reduce unnecessary notation, throughout the paper define the interval $[b, c]$ as $[0, c]$ whenever $b<0$ and as the empty set whenever $b>c$ or $c<0$. Similarly define open intervals.

Lemma 1. Non-binding campaign spending cap.

(a) if $\alpha \in\left(0, \frac{\eta_{2}}{\beta_{2}}-\frac{\eta_{1}}{\beta_{1}}\right)$ then $\vartheta=\max \left(\frac{1}{\beta_{1}}, M_{2}\left(\frac{1}{\beta_{1}}\right)\right)$ and $k>\vartheta$ is

not binding and $\bar{a}_{1}<M_{1}\left(\bar{a}_{2}\right)$ and $a_{1}^{\text {sup }}=\frac{1}{\beta_{1}}$ and $a_{2}^{\text {sup }}=M_{2}\left(\frac{1}{\beta_{1}}\right)$.

(b) if $\alpha \in\left[\frac{\eta_{2}}{\beta_{2}}-\frac{\eta_{1}}{\beta_{1}}, \frac{\eta_{2}}{\beta_{2}}\right)$ then $\vartheta=\max \left(M_{1}\left(\frac{1}{\beta_{2}}\right), \frac{1}{\beta_{2}}\right)$ and $k>\vartheta$ is not

binding and $\bar{a}_{1} \geq M_{1}\left(\bar{a}_{2}\right)$ and $a_{1}^{\text {sup }}=M_{1}\left(\frac{1}{\beta_{2}}\right)$ and $a_{2}^{\text {sup }}=\frac{1}{\beta_{2}}$.

\section{Proof. Appendix.}

Absent a binding cap on spending, the identity of the strong candidate depends on the degree of initial voter disposition advantage and candidates' cost of raising funds per effective unit of spending. Here is a sketch of the Proof of Lemma 1. Since there is no binding legal restriction on the level of spending, each candidates' maximum feasible spending at which the valuation from winning is non-negative $\left(\bar{a}_{i}\right)$ is given by $1 / \beta_{i}$. There exists a range of $\alpha \in\left(0,\left(\eta_{2} / \beta_{2}-\eta_{1} / \beta_{1}\right)\right)$ where Candidate 2 is strong $\bar{a}_{1}<M_{1}\left(\bar{a}_{2}\right)$ if Candidate 2 has a lower cost of raising funds per effective unit of spending, $\eta_{2} / \beta_{2}>\eta_{1} / \beta_{1}$. In other words, despite a mild initial voter disposition disadvantage, Candidate 2 has the option of guaranteeing victory with a positive payoff if his cost per effective unit of spending is lower. Candidate 2 is weak if $\alpha \in\left[\left(\eta_{2} / \beta_{2}-\eta_{1} / \beta_{1}\right), \eta_{2} / \beta_{2}\right)$. The supremum of the support of the weak candidate $j$ 's equilibrium mixed strategy is given by $1 / \beta_{j}$. If it were lower than $1 / \beta_{j}$, the strong candidate $i$ would never spend more than just enough to exceed the score of the weak candidate at the supremum of $j$ 's equilibrium mixed strategy support. The weak candidate would then have an incentive to deviate by increasing his upper bound to guarantee a win increasing his expected payoff. Since the supremum of the equilibrium support of the weak candidate $j$ is given by $1 / \beta_{j}$, the strong candidate's supremum is $M_{i}\left(\frac{1}{\beta_{j}}\right)$.

Lemma 2 provides conditions determining which candidate is strong when there is a binding cap. With a binding cap asymmetries in campaign spending effectiveness and in fundraising efficiency have qualitatively distinct effects on the equilibrium of the contest. While fundraising efficiency determines the maximum willingness to spend, the variation in the effectiveness in campaign spending determines the identity of the strong candidate when there is a binding cap.

Lemma 2. With a binding campaign spending cap $(\mathrm{k} \leq \vartheta)$ :

(a) if $k\left(\eta_{2}-\eta_{1}\right)<\alpha$ then $\bar{a}_{1} \geq M_{1}\left(\bar{a}_{2}\right)$.

(b) if $k\left(\eta_{2}-\eta_{1}\right)>\alpha$ then $\bar{a}_{1}<M_{1}\left(\bar{a}_{2}\right)$.

\section{Proof. Appendix.}

Candidate 1 is strong if $k\left(\eta_{2}-\eta_{1}\right)<\alpha$. At an intuitive level, a very restrictive binding cap limits Candidate 2's ability to overcome Candidate 1 's initial voter disposition advantage. Even if Candidate 2 is more effective in campaign spending, Candidate 2 must outspend Candidate 1 to be able to match the Candidate 1 's score as long as $k\left(\eta_{2}-\eta_{1}\right)<\alpha$. The mirror argument is that Candidate 1 does not need to spend more than $M_{1}(k)<k$ if Candidate 2 is restricted by the cap. Candidate 1 is therefore not effectively restricted by the cap. This allows Candidate 1 to capture the strong position.

If $k\left(\eta_{2}-\eta_{1}\right)>\alpha$, however, Candidate 2 is strong. Note that this case can only exist if Candidate 2 has higher spending effectiveness, $\eta_{2}>\eta_{1}$. If the cap is not too restrictive, Candidate 2 can use his greater effectiveness to capture the strong position in the competition. If Candidate 2 were to spend $k$, Candidate 1 would need to outspend Candidate 2 to match his score, but would not be permitted by law. If Candidate 1 is restricted by $k$, Candidate 2 would not need to spend as much as $k$, since $M_{2}(k)<k$. Hence the spending cap would effectively only constrain Candidate 1 .

Note that with a binding cap, only the weak candidate $j$ is effectively restricted by the cap and his rival $i$ is able to use that to capture the strong position in the contest. If the weak candidate $j$ is effectively restricted by $k$, then the strong candidate $i$ does not spend more than $M_{i}(k)<k$. The reversed inequality, $M_{i}(k)>k$, would be a contradiction of $j$ being the weak candidate.

Proposition 1. For $k>\alpha / \eta_{2}$ and $\alpha \in\left(0, \frac{\eta_{2}}{\beta_{2}}\right)$ : if $\bar{a}_{1} \geq M_{1}\left(\bar{a}_{2}\right)$ then the equilibrium is characterized by unique cumulative density functions $F_{1}$ $\left(a_{1}\right)$ and $F_{2}\left(a_{2}\right)$ for Candidates 1 and 2 's campaign spending respectively:

$$
\begin{aligned}
& F_{1}\left(a_{1}\right)= \begin{cases}\frac{\beta_{2}}{\eta_{2}}\left(\alpha+\eta_{1} a_{1}\right) & \text { for } a_{1} \in\left[0, M_{1}\left(\bar{a}_{2}\right)\right] \\
1 & \text { for } a_{1} \in\left(M_{1}\left(\bar{a}_{2}\right), \infty\right)\end{cases} \\
& F_{2}\left(a_{2}\right)= \begin{cases}1-\frac{\beta_{1}}{\eta_{1}}\left(\eta_{2} \bar{a}_{2}-\alpha\right) & \text { for } a_{2} \in\left[0, \alpha / \eta_{2}\right] \\
1-\frac{\beta_{1}}{\eta_{1}} \eta_{2} \bar{a}_{2}+\frac{\beta_{1} \eta_{2}}{\eta_{1}} a_{2} & \text { for } a_{2} \in\left(\frac{\alpha}{\eta_{2}}, \bar{a}_{2}\right] \\
1 & \text { for } a_{2} \in\left(\bar{a}_{2}, \infty\right)\end{cases}
\end{aligned}
$$

(a) Expected payoffs: $E V_{1}=1-\frac{\beta_{1}}{\eta_{1}}\left(\eta_{2} \bar{a}_{2}-\alpha\right) \geq 0$, with equality only if $\bar{a}_{1}=M_{1}\left(\bar{a}_{2}\right)$, and $\mathrm{EV}_{2}=0$. (b) Expected spending: $E\left(a_{1}\right)=\frac{\beta_{2} \eta_{1}}{2 \eta_{2}}$ $\left[\left(\eta_{2} \bar{a}_{2}-\alpha\right) / \eta_{1}\right]^{2}+\left(1-\beta_{2} \bar{a}_{2}\right)\left[\left(\eta_{2} \bar{a}_{2}-\alpha\right) / \eta_{1}\right]$ and $E\left(a_{2}\right)=\frac{\beta_{1} \eta_{2}}{2 \eta_{1}}\left[\bar{a}_{2}^{2}-\right.$ $\left.\left(\frac{\alpha}{\eta_{2}}\right)^{2}\right]$. (c) Probability that Candidate 2 wins: $\operatorname{prob}_{2}=\frac{1}{2} \frac{\beta_{2} \beta_{1} \eta_{2}}{\eta_{1}}$ $\left[\bar{a}_{2}^{2}-\left(\frac{\alpha}{\eta_{2}}\right)^{2}\right]$.

Proof. Appendix.

The equilibrium distribution functions with a binding cap are graphed in Fig. 1. In equilibrium contestants are indifferent between all spending levels in the support of their equilibrium strategies given the equilibrium distribution of their rival. Since $\bar{a}_{1} \geq M_{1}\left(\bar{a}_{2}\right)$, Candidate 1 is strong. He never exceeds $M_{1}(k)^{+}$since the weak candidate (Candidate 2) is restricted by $k, a_{2}^{\text {sup }}=\bar{a}_{2}=k$.

Candidate 2 never spends in the range $\left(0, \alpha / \eta_{2}\right)$, since he needs to spend at least $\alpha / \eta_{2}$ in order to overcome the initial voter disposition advantage of Candidate 1. Both the weak and the strong candidates have a probability mass at zero campaign spending. The probability masses at zero are increasing in $\alpha$. The higher is Candidate 1's initial disposition advantage, the greater is the chance that Candidate 2 is 


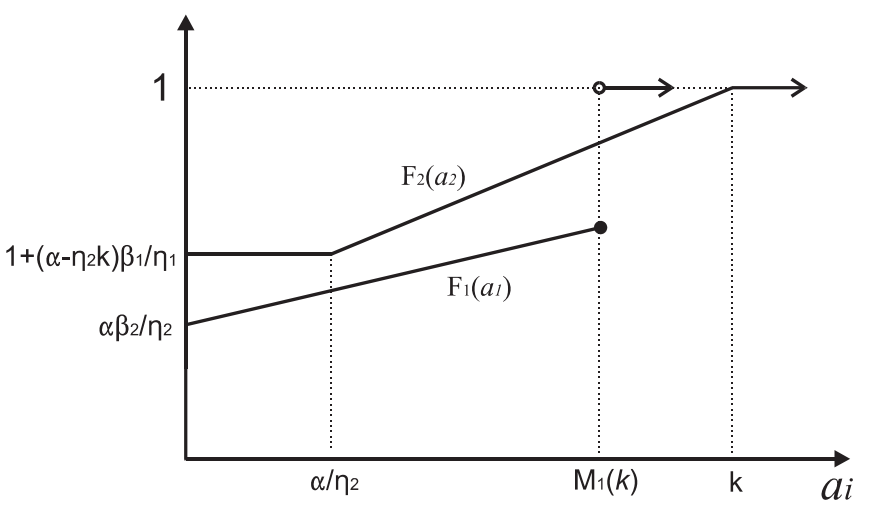

Fig. 1. Equilibrium distributions with a binding cap when Candidate 1 is strong.

passive in his campaign effort which allows Candidate 1 to remain passive in campaign spending with positive probability.

Proposition 2. For $k>\alpha / \eta_{2}$ and $\alpha \in\left(0, \frac{\eta_{2}}{\beta_{2}}\right):$ if $\bar{a}_{1}<M_{1}\left(\bar{a}_{2}\right)$ then the equilibrium is characterized by unique cumulative density functions $F_{1}\left(a_{1}\right)$ and $F_{2}\left(a_{2}\right)$ for Candidates 1 and 2's campaign spending respectively:

$F_{1}\left(a_{1}\right)= \begin{cases}1-\frac{\beta_{2}}{\eta_{2}} \eta_{1} \bar{a}_{1}+\frac{\beta_{2} \eta_{1}}{\eta_{2}} a_{1} & \text { for } a_{1} \in\left[0, \bar{a}_{1}\right] \\ 1 & \text { for } a_{2} \in\left(\bar{a}_{1}, \infty\right)\end{cases}$
$F_{2}\left(a_{2}\right)= \begin{cases}0 & \text { for } a_{2} \in\left[0, \alpha / \eta_{2}\right] \\ \frac{\beta_{1}}{\eta_{1}}\left(\eta_{2} a_{2}-\alpha\right) & \text { for } a_{2} \in\left(\frac{\alpha}{\eta_{2}}, M_{2}\left(\bar{a}_{1}\right)\right] \\ 1 & \text { for } a_{2} \in\left(M_{2}\left(\bar{a}_{1}\right), \infty\right) .\end{cases}$

(a) Expected payoffs: $E V_{1}=0$, and $E V_{2}=1-\frac{\beta_{2}}{\eta_{2}}\left(\eta_{1} \bar{a}_{1}+\alpha\right)>0$. (b) Expected spending: $E\left(a_{1}\right)=\frac{\eta_{1} \beta_{2} \bar{a}_{1}^{2}}{2 \eta_{2}}$ and $E\left(a_{2}\right)=\frac{\beta_{1} \bar{a}_{1}}{2 \eta_{2}}\left(\eta_{1} \bar{a}_{1}+\right.$ $2 \alpha)+\frac{1}{\eta_{2}}\left(1-\beta_{1} \bar{a}_{1}\right)\left(\eta_{1} \bar{a}_{1}+\alpha\right)$. (c) Probability that Candidate 2 wins: prob $_{2}=1-\frac{1}{2} \frac{\beta_{2} \beta_{1} \eta_{1} \bar{a}_{1}^{2}}{\eta_{2}}$.

Proof. Appendix.

The equilibrium distribution functions with a binding cap are graphed in Fig. 2. Candidate 2 is strong since $\bar{a}_{1}<M_{1}\left(\bar{a}_{2}\right)$. This case is possible only if the initial disposition advantage of Candidate 1 is mild

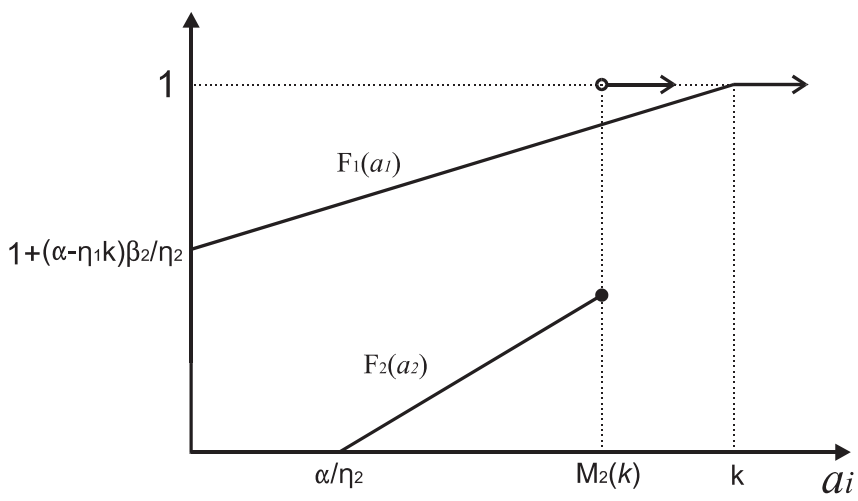

Fig. 2. Equilibrium distributions with a binding cap when Candidate 2 is strong. and Candidate 2 is more effective in campaign spending (see Lemma 2 Part $a$ ). Candidate 2 never exceeds $M_{2}(k)^{+}$since Candidate 1 is restricted by $k, a_{1}^{\text {sup }}=\bar{a}_{1}=k$. Hence the strong candidate is not effectively restricted by the cap while the weak candidate is.

When Proposition 2 applies, note that Candidate 2's win probability does not depend on the degree of initial voter disposition advantage (see Proposition 2 Part $c$ ). If $\alpha$ increases, Candidate 2 simply becomes more aggressive in order to overcome his rival's greater head start while Candidate 1's equilibrium distribution remains the same. For parameter values where Proposition 1 applies, however, the probability of victory does depend on the degree of initial voter disposition advantage. The strong position of Candidate 1 allows him to compete away all of 2's expected gains. Thus if $\alpha$ increases, Candidate 2 does not become more aggressive to compensate. This allows Candidate 1 to reduce his campaign spending and still have a higher probability of winning than he did with a lower $\alpha$.

The model implies that it may be difficult to empirically establish whether an existing spending limit is binding. Natural intuition would suggest that there would be a large number of political candidates who spend the maximum permissible amount if the cap were binding. For instance Evens (2007) reports that campaign spending limits are seldom binding based on the fact that candidates so rarely spend at the limit. ${ }^{11}$ However a significant feature of the equilibrium is that a binding cap alters both candidates' behavior but neither candidate has a probability mass at the cap. Hence according to the model, these empirical observations do not necessarily indicate that the limits are not binding.

\section{Equilibrium implications}

In this section we discuss the equilibrium implications of the model for the set of parameter values that are consistent with empirical regularities.

\subsection{Incumbency advantage}

When quality differences are controlled for incumbents tend to have a higher probability of victory. Jamie et al. (2007) finds an incumbency advantage of roughly three percent using late-nineteenth-century US House election data; Levitt (1994) finds an incumbency advantage between three and four percent in US House races from 1972 to 1990 and finds an incumbency advantage of four to five percent points. Political science regards this incumbency advantage as a cause of concern since the uneven playing field can cause adverse welfare effects reducing the accountability of the incumbent occupying a safe seat and deteriorating incoming politician quality.

To focus on the effect of a spending limit on incumbency advantage, we consider two candidates who are identical in every respect except for their incumbency status. Hence asymmetries in initial voter disposition advantage, effectiveness in campaign spending and efficiency in fundraising are driven solely by incumbency status. We label Candidate 1 as the incumbent since empirically incumbents tend to enjoy the initial voter disposition advantage either due to reputations they build over their term in office or due to their campaign activities in prior elections. ${ }^{12}$

We define the "degree of incumbency advantage" in the electoral contest as the incumbent's probability of victory minus $1 / 2$. Using this definition, if the degree of incumbency advantage is positive, then there is "incumbency advantage."

\footnotetext{
${ }^{11}$ Combining all Canadian federal races in the 1997 and 2000 election years, Milligan and Rekkas (2008) report that $89 \%$ of all candidates and $66 \%$ of incumbents spent less than $90 \%$ of their spending limit.

12 Jacobson (1981) reports that $50 \%$ of the sampled voters recalled the incumbent's name, while only $17 \%$ of the voters recalled the challenger's name. $40 \%$ of the voters claimed that family or friends had contact with the incumbent. The same figure for the challenger was only $11 \%$.
} 
Lemma 3. In the absence of a binding campaign spending cap, there is incumbency advantage, $\operatorname{prob}_{1}>1 / 2$, if:

$$
\begin{aligned}
& \text { (a) } \frac{\eta_{1}}{\beta_{1}} \geq \frac{\eta_{2}}{\beta_{2}} \\
& \text { (b) } \frac{\eta_{1}}{\beta_{1}}<\frac{\eta_{2}}{\beta_{2}} \text { and } \alpha \in\left(\left(\frac{\eta_{2}}{\beta_{2}}\left(\frac{\eta_{2}}{\beta_{2}}-\frac{\eta_{1}}{\beta_{1}}\right)\right)^{1 / 2}, \frac{\eta_{2}}{\beta_{2}}\right)
\end{aligned}
$$

Proof. Appendix.

If the cost of raising funds for one effective unit of spending is lower for the incumbent, $\eta_{1} / \beta_{1} \geq \eta_{2} / \beta_{2}$, then without a cap there is incumbency advantage in the contest, however small voters' predisposition for the incumbent may be. If the cost of raising funds for one effective unit of spending is lower for the challenger, then there is incumbency advantage without a cap only if the incumbent's initial voter disposition advantage is sufficiently high. In both these cases, in the absence of a binding spending limit the playing field is not level. It is tilted in favor of the incumbent.

Before we move on to the analysis of the effect of a spending limit on the probability of victory of the incumbent, it may be helpful to present the main intuition driving the results: Whether or not the imposition of a spending limit can help to level the playing field depends on the identity of the candidate whose supremum of the support of his equilibrium mixed strategy is higher in the absence of a cap. As long as one candidate as a higher supremum spending in equilibrium he would be restricted by the introduction of a barely binding cap whereas the rival would not be effectively constrained. Hence the rival would benefit from the imposition of a barely binding cap. If the incumbent's supremum of the support of his no-cap equilibrium mixed strategy is higher than the challenger's, the imposition of a limit can help reduce the probability of victory of the incumbent. Otherwise the limit increases the probability of victory of the incumbent.

In this subsection we present three results exploring the implications of the equilibrium. Each result is followed by a short discussion on whether a campaign spending limit can level the playing field when there is incumbency advantage in the absence of a cap.

Result 1. If $\eta_{1} \geq \eta_{2}$, then imposing a binding spending cap and/or making a binding cap more restrictive increases the probability of victory and expected payoff for the incumbent as long as the incumbent has any initial voterdisposition advantage, however small: $\frac{\Delta P r o b_{1}}{\Delta k}<0$ and $\frac{\Delta E V_{1}}{\Delta k}<0$. This result holds regardless of the candidates' relative fundraising abilities. $A$ more restrictive cap reduces expected aggregate spending, $\frac{\Delta E\left(a_{1}+a_{2}\right)}{\Delta k}>0$.

\section{Proof. Appendix.}

This result holds whether or not there is incumbency advantage in the absence of a spending limit. If the incumbent is more effective in campaign spending the imposition of a spending limit and/or the tightening of the limit further, always increases the probability of victory of the incumbent. On the positive side, the limit succeeds in reducing expected aggregate spending.

If $\eta_{1} \geq \eta_{2}$, without a spending cap either Proposition 1 or 2 may apply depending on the candidates' relative efficiency in fundraising. However with a binding cap Candidate 1 is strong, so Proposition 1 applies regardless of relative fundraising efficiency. Since the incumbent is more efficient in converting spending into votes and he has an initial voter disposition advantage, the challenger must spend more than the incumbent in order to effectively match his score, $M_{2}\left(a_{1}\right)>a_{1}$. With or without a cap, the supremum of the support of equilibrium mixed strategy of Candidate 2 is higher than the supremum of the incumbent's. Hence the cap restricts the challenger while the incumbent is effectively unrestricted. This advantage allows the incumbent to capture a positive expected payoff from the contest equal to $1-\beta_{1} M_{1}(k)$ (see Proposition 1 part $a$ ). The challenger becomes more constrained as the cap becomes more restrictive which is to the advantage of the incumbent who is popular a priori. This decreases the overall aggressiveness of the challenger, which in turn induces less aggressive spending from the incumbent, leading to decreased expected aggregate spending. With a more restrictive cap, the incumbent's probability of winning goes up and expected total campaign spending goes down.

This result is different from Proposition 6 in Meirowitz (2008) where there is no initial voter disposition advantage. Meirowitz (2008) finds that the cap benefits the challenger when the candidates only differ in efficiency of fundraising as long as voters resolve ties in favor of the challenger. Without an initial voter disposition advantage, candidates tie when they both spend at the limit. This is not the case with $\alpha>0$, even if $\eta_{1}=\eta_{2}$ as in Meirowitz (2008). We find that the $a$ priori popular incumbent with $\eta_{1} \geq \eta_{2}$, always benefits from the cap, irrespective of the candidates' relative fundraising efficiency, because the cap only effectively restricts his rival.

The main argument of the proponents of spending limits is that caps put candidates with lesser means on an equal footing. The main argument of opponents is that caps limit challenger's ability to overcome incumbent's head start with the voters. Result 1 shows that if $\eta_{1} \geq \eta_{2}$, the argument of the opponents of caps always trumps the main argument in favor of caps. No matter how dramatic the difference in fundraising abilities, the cap always benefits the incumbent with the initial voter disposition advantage, no matter how small that advantage may be. Hence the primary argument in favor of caps needs qualifications at best.

In what follows we allow for $\eta_{1}<\eta_{2}$. Indeed there is vast empirical evidence indicating that, controlling for candidate quality, challengers tend to have higher effectiveness of campaign spending. ${ }^{13}$ Incumbents are already known by the electorate. However challengers often must still establish name recognition. This provides an additional benefit to campaigning for challengers.

In addition to the initial voter disposition advantage, incumbents also tend to have higher efficiency in fundraising since they are in a position to deliver political favors to donors. Hence we discuss the equilibrium implications for $\beta_{2}>\beta_{1} \cdot{ }^{14}$ Note that this captures the source of asymmetry that forms the main argument made in favor of spending caps.

Result 2. If $\beta_{1}<\beta_{2}$ and $\eta_{1}<\eta_{2}$, and the incumbent has a large initial voter disposition advantage, $\alpha \in\left[\frac{\eta_{2}-\eta_{1}}{\beta_{2}}, \frac{\eta_{2}}{\beta_{2}}\right)$, the imposition of a binding campaign spending cap and/or making a binding cap more restrictive increases the probability of victory and the expected payoff of the incumbent and reduces expected spending, $\frac{\Delta \text { Prob }_{1}}{\Delta k}<0$ and $\frac{\Delta \mathrm{EV}_{1}}{\Delta k}<0$ and $\frac{\Delta \mathrm{E}\left(a_{1}+a_{2}\right)}{\Delta k}<0$.

Proof. Appendix.

For the empirically relevant parameter values where there is incumbency advantage without a cap, Result 2 shows that a spending cap does not achieve its stated aim. ${ }^{15} \mathrm{~A}$ cap exacerbates incumbency

\footnotetext{
${ }^{13}$ In addition to the discussion in the introduction, Erikson and Palfrey (1998) and Samuels (2001) show that the effectiveness of incumbent spending declines with seniority, giving further evidence for the hypothesis that the marginal benefit of spending declines with name recognition

14 Palda (1992) shows that the larger the government wealth in control of the politician and the more power the politician has over the state budget, the more money the politician raises for his campaign. Hall and Wayman (1990) show that politicians with positions of power in congressional committees are better fundraisers. ${ }^{15}$ If $\beta_{1}<\beta_{2}$ and $\eta_{1}<\eta_{2}$ while $\eta_{1} / \beta_{1} \geq \eta_{2} / \beta_{2}$, then by Lemma 3 Part $(a)$ there is incumbency advantage in the absence of a cap. Hence for the entire range of $\alpha \in\left[\left(\eta_{2}-\right.\right.$ $\left.\eta_{1}\right) / \beta_{2}, \eta_{2} / \beta_{2}$ ) specified in Result 2 , there is incumbency advantage without a cap and the imposition and/or the restriction of a binding cap increases the probability of victory and the expected payoff of the incumbent. If $\beta_{1}<\beta_{2}$ and $\eta_{1}<\eta_{2}$ while $\eta_{1} / \beta_{1}<\eta_{2} /$ $\beta_{2}$, then there is incumbency advantage without a cap for $\alpha$ specified by Lemma 3 Part (b). The intersection of the range of $\alpha$ specified by Lemma 3 Part (b) and the range of $\alpha$ specified in Result 2 yields $a \in\left(\max \left(\frac{\eta_{2}-\eta_{2}}{\beta_{2}},\left(\frac{\eta_{2}}{\beta_{2}}\left(\frac{\eta_{2}}{\beta_{2}}-\frac{\eta_{1}}{\beta_{1}}\right)\right)^{1 / 2}\right), \frac{\eta_{2}}{\beta_{2}}\right)$. In this range there is incumbency advantage in the absence of a cap and the imposition and/or the restriction of a binding cap increases the probability of victory and the expected payoff of the incumbent.
} 
advantage; It gives a boost to the incumbent, making it less likely for the challenger to win the election. However, a more restrictive cap does help reduce expected aggregate spending.

In the range of $\alpha$ specified in Result 2, Proposition 1 applies with and without a spending cap. The large initial voter disposition advantage overwhelms the challenger's higher effectiveness in spending. Even though the challenger is more efficient in spending, he starts out so far behind (due to the large $\alpha$ ) that he must outspend his rival in order to catch up. The campaign spending cap limits his ability to do so. The supremum of the support of challenger's equilibrium mixed strategy exceeds that of the incumbent's since the challenger needs to spend more than the incumbent to overcome the large initial voter disposition advantage. A binding cap restricts Candidate 2 but does not effectively restrict Candidate 1 . The expected spending of Candidate 2 decreases which allows the incumbent to relax and the incumbent's expected spending decreases, as well. This leads to an increase in the expected payoff of the contest to the incumbent. The more restrictive the ceiling, the higher is the expected payoff and the probability of victory of the incumbent.

Under the parameter values of Results 1 and 2, limits not only fail to improve fairness in the elections but they also give an additional hand to the incumbents who are already advantaged. Looking at the Canadian case, Palda and Palda (1985) suggest that "[t]he legislation of ceilings seems a reasonable democratic exercise. Yet it is curious that such a law should have found the support of so many holders of elected office. It is, after all, incumbents who apparently stand to benefit least from a cap on their spending. Nevertheless, it is from incumbents at federal and provincial levels, and without obvious pressure from the public, that the impetus for these laws has come." The cap does not achieve its stated aim. It increases incumbency advantage. However, as Result 3 below shows the cap can decrease incumbency advantage if the incumbent has a mild initial voter disposition advantage and the cap is not too restrictive. When the cap is not binding the incumbent is strong. However with a moderate binding cap the challenger captures the strong position. And with a very restrictive cap, the initial voter disposition advantage overwhelms the effectiveness advantage of the challenger and the incumbent captures the strong position.

Result 3. If $\beta_{1}<\beta_{2}$ and $\eta_{1}<\eta_{2}$, and the incumbent has a mild initial voter disposition advantage, $\alpha \in\left(\frac{\eta_{2}}{\beta_{2}}-\frac{\eta_{1}}{\beta_{1}}, \frac{\eta_{2}-\eta_{1}}{\beta_{2}}\right)$, as long as the cap is moderate $k>\frac{\alpha}{\eta_{2}-\eta_{1}}$, the imposition of a cap and/or making a binding cap more restrictive decreases incumbent's probability of victory and expected payoff. But imposing a very restrictive cap, $k<\frac{\alpha}{\eta_{2}-\eta_{1}}$, or making such a cap more restrictive, benefits the incumbent both in the win probability and in the expected payoff. The effect of a spending limit on expected spending is non-monotonic as well.

Proof. Appendix.

For a subset of parameter values in Result 3, there is incumbency advantage in the absence of a spending limit. ${ }^{16}$ When there is incumbency advantage without a cap, a more restrictive cap can reduce the probability of victory of the incumbent as long as the cap is moderate. However a very restrictive cap enhances the electoral prospects of the incumbent.

To prove Result 3, the appendix establishes that: (a) The introduction of a barely binding spending limit leads to a jump

\footnotetext{
${ }^{16}$ If $\beta_{1}<\beta_{2}$ and $\eta_{1}<\eta_{2}$ while $\eta_{1} / \beta_{1} \geq \eta_{2} / \beta_{2}$, then by Lemma 3 Part (a) there is incumbency advantage in the absence of a cap $\forall \alpha \in\left(0, \eta_{2} / \beta_{2}\right)$. If $\beta_{1}<\beta_{2}$ and $\eta_{1}<\eta_{2}$ while $\eta_{1} / \beta_{1}<\eta_{2} / \beta_{2}$, then there is incumbency advantage without a cap for $\alpha$ specified by Lemma 3 Part $(b)$ which is a subset of the range of $\alpha$ specified in Result 3. To see this note that $\left(\frac{\eta_{2}}{\beta_{2}}-\frac{\eta_{1}}{\beta_{1}}\right)<\left(\frac{\eta_{2}}{\beta_{2}}\left(\frac{\eta_{2}}{\beta_{2}}-\frac{\eta_{1}}{\beta_{1}}\right)\right)^{1 / 2}<\frac{\eta_{2}-\eta_{1}}{\beta_{2}}$ if $\frac{\beta_{2}-\beta_{1}}{\beta_{1}}>\frac{\left(\eta_{2}-\eta_{1}\right)}{\eta_{2}}$, i.e. if the fundraising advantage of the incumbent is significant in comparison to the effective spending advantage of the challenger.
}

down in the incumbent's probability of victory and in his expected payoff and it leads to a jump up in expected total campaign spending. (b) As long as the limit is moderate, a more restrictive limit causes a decrease in the incumbent's probability of victory, an increase in the challenger's expected payoff and a decrease in expected total spending. (c) A reduction in the limit from $\alpha /\left(\eta_{2}-\eta_{1}\right)^{+}$to $\alpha /\left(\eta_{2}-\right.$ $\left.\eta_{1}\right)^{-}$leads to a jump up in the incumbent's probability of victory, in his expected payoff and in his expected campaign spending. Further reductions in the spending limit decrease both candidates' expected spending but increase the incumbent's expected payoff and probability of victory.

For parameter values specified in Result 3 Figs. 3-5 graph candidates' expected payoffs, their expected campaign spending and the challenger's probability of victory as a function of the level of the cap.

The identity of the strong candidate depends on the level of the cap. When the cap is not binding, the incumbent is the strong candidate and Proposition 1 describes the equilibrium. When the cap is binding at a moderate level, the playing field is tilted in favor of the challenger who is more effective in campaign spending and the equilibrium is characterized in Proposition 2. With a tight spending ceiling, it is the incumbent who captures the strong position due to his initial voter disposition advantage and the equilibrium is once again given by Proposition 1 (see Lemma 2).

The supremum of the support of the incumbent's no-cap equilibrium mixed strategy is higher than of the challenger's, $M_{1}\left(\frac{1}{\beta_{2}}\right)>\frac{1}{\beta_{2}}$, since the incumbent needs to be aggressive in order to overcome the superior campaign spending effectiveness of the challenger. Hence when the ceiling becomes barely binding, the limit restricts the incumbent but does not effectively restrict the challenger. Since the incumbent is restricted by the cap, the challenger can guarantee a win by exceeding the supremum score of the incumbent. This drives the expected payoff of the incumbent down to zero (Fig. 3), and yields a positive expected payoff for the challenger. The imposition of the ceiling changes the identity of the strong candidate. The cap tilts the playing field in favor of the challenger which makes the challenger more aggressive in campaign spending; resulting in a jump up in the expected spending of the challenger (Fig. 4). This yields a jump up in the probability that the challenger wins (Fig. 5). The imposition of the spending cap benefits the challenger. ${ }^{17}$

As long as the cap is moderate, a further decrease in the spending cap leads to a decline in expected spending of both candidates and the expected payoff of the challenger goes up. Just at $k=\alpha /\left(\eta_{2}-\eta_{1}\right)$ however, the identity of the strong candidate switches from the challenger to the incumbent. Even though the challenger is more

\footnotetext{
${ }^{17}$ Result 3 also holds for alternative contest success functions which yield equilibrium in pure strategies. For instance consider the natural head-start advantage extension of the Tullock (1980) contest success function used in Konrad (2002) where player $i$ 's probability of victory is $s_{i} /\left(s_{i}+s_{j}\right)$ and $s$ is the candidate's score: $s_{1}=\alpha+\eta_{1} a_{1}$ and $s_{2}=\eta_{2} a_{2}$. If all spending is banned the challenger would have no opportunity to compete with the incumbent's initial voter disposition advantage. Hence relaxing the cap would provide an opportunity for the challenger to compete and thus increase his probability of victory. If there were no cap on spending, the candidates' Kuhn-Tucker conditions (requiring $a_{i} \geq 0$ ) yield positive spending if $\alpha<\eta_{2} / \beta_{2}$. In equilibrium $a_{1}=\left[\beta_{2} \eta_{1} \eta_{2} /\left(\beta_{1} \eta_{2}+\beta_{2} \eta_{1}\right)^{2}\right]-\left(\alpha / \eta_{1}\right)$ and $a_{2}=\left[\beta_{1} \eta_{1} \eta_{2} /\left(\beta_{1} \eta_{2}+\beta_{2} \eta_{1}\right)^{2}\right]$. Therefore in the absence of a spending limit $a_{1}>a_{2}$ if $\alpha<\frac{\left(\beta_{2}-\beta_{1}\right) \eta_{1}^{2} \eta_{2}}{\left(\beta_{1} \eta_{2}+\beta_{2} \eta_{1}\right)^{2}}$. In this case the imposition of a barely binding cap directly affects only Candidate 1 . The effect on Candidate 2 through Candidate 1's spending is of second order. Hence a barely binding cap would increase the expected value and probability of victory of Candidate 2 . The above yields a condition analogous to the condition in Result 3. If $\beta_{1}<\beta_{2}, \alpha$ is sufficiently small, then the initial imposition of the limit will increase the probability that the challenger wins, but a complete ban on spending will guarantee victory for the incumbent. However, when $\beta_{1} \geq \beta_{2}$ and/or when $\alpha$ is sufficiently large, in the absence of a spending limit $a_{1}<a_{2}$. Then the imposition of a barely binding limit restricts the challenger which benefits the incumbent, suggesting that results analogous to Results 1 and 2 continue to hold in this environment.
} 


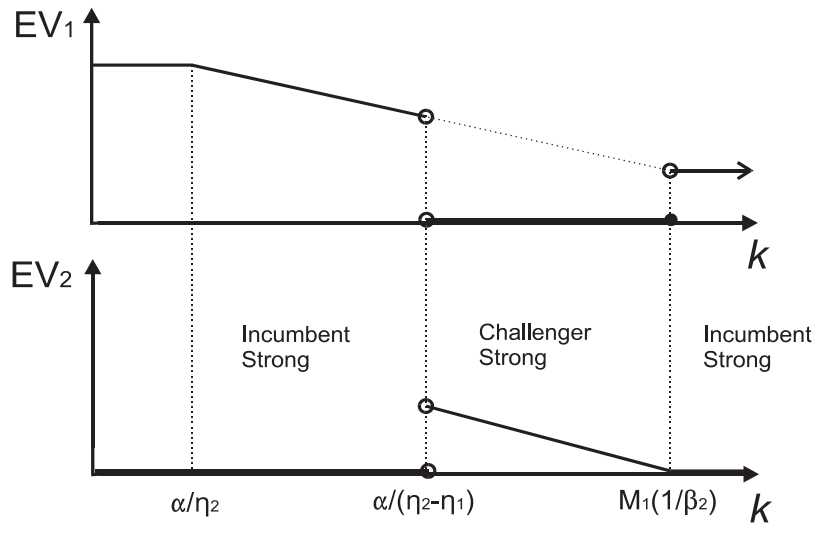

Fig. 3. Expected payoffs of incumbent and challenger.

effective in spending, the cap is too small for the challenger to catch up with rival's initial voter disposition advantage. The playing field tilts in favor of the incumbent which induces more aggressive campaign spending of the incumbent.

For the parameter values in Result 3, when there is incumbency advantage in the absence of a cap, with a moderate cap the probability that the challenger wins exceeds $1 / 2$. Whether this theoretical prediction is empirically relevant depends on the interpretation of the source of asymmetry in spending effectiveness. The only source of advantage for the challenger that can help him to catch up with the incumbent's head-start advantage is the challenger's superior campaign spending effectiveness. The challenger may have higher spending effectiveness because campaign spending has the additional benefit of establishing name recognition while the incumbent already enjoys name recognition. Under this interpretation of the source of the challenger's spending efficiency, it is not believable that he would have a greater than $1 / 2$ chance of victory. At best he would be able to catch up to the incumbent. Once he establishes the same level of name recognition his efficiency of spending would be the same as the incumbent's. Hence this counterintuitive prediction is due to the linear technology of spending effectiveness. In order to capture this interpretation of asymmetry in campaign spending, one would need to specify a technology with decreasing returns. ${ }^{18}$

However under other interpretations for the source of the asymmetry in spending effectiveness a greater than $1 / 2$ chance of winning for the challenger may be plausible. For example, the incumbent has pre-established impressions in voters' minds over the years he has been in office whereas the challenger is a blank page. Changing people's minds may be harder than creating a first impression. ${ }^{19}$ With this interpretation for the asymmetry in $\eta$, the challenger may capture the strong position with a higher chance of victory if the head-start advantage is not too severe.

Finally, if the incumbent's initial voter disposition advantage is small, $\alpha \in\left(0, \frac{\eta_{2}}{\beta_{2}}-\frac{\eta_{1}}{\beta_{1}}\right)$, without a spending limit the spending effectiveness advantage of the challenger overwhelms the initial voter disposition advantage and the fundraising efficiency advantage of the incumbent (see Lemma 1 part a). In this case, without a spending limit, the challenger has a higher probability of winning.

\footnotetext{
18 Alternatively one may consider a strictly increasing concave score function. Pastine and Pastine (2011) provide payoff characterization of constrained all-pay contests allowing for general score functions. The player with the highest reach, i.e. the highest feasible score at which his valuation for winning is non-negative, captures positive expected payoff. And the other player has an expected payoff equal to zero. Hence the form of the score function is irrelevant for the expected payoff results. However there are no general results so far on the win probability and on expected spending for constrained all-pay contests with concave score functions.

19 The Democratic Party primary elections in 2008 between Senators Hillary Clinton and Barack Obama may be a good example of this.
}

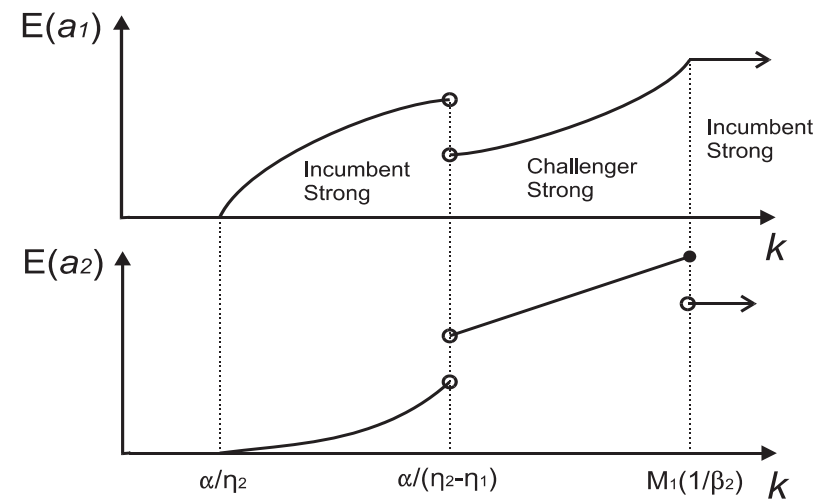

Fig. 4. Expected spending of incumbent and challenger.

This violates the empirical regularity that incumbents tend to have a higher probability of victory than challengers when there is no spending limit.

\subsection{Candidate quality}

In the discussion above we examined the effect of a spending limit on incumbency advantage unhampered by candidate quality differences where candidate asymmetries were driven by incumbency status only. Now we briefly consider spending limits where candidates differ in quality and the key parameters of the model reflect candidate quality unhampered by incumbency status. Many desirable candidate qualities such as leadership skills and the ability to persuade people, improve the campaign spending effectiveness of a candidate. Experience in public service and previous accomplishments may also be associated with candidate quality and they tend to improve name recognition. Hence campaign spending effectiveness and favorable initial voter disposition are likely to be positively correlated with candidate quality. The relation between candidate quality and fundraising efficiency is not as clear-cut. While a highquality candidate is likely to be good fundraiser due to effective communication skills, a self-serving low-quality candidate may have an easy time raising funds from special interest groups in return for political favors. However, the following Corollary to Result 1 holds irrespective of how quality affects fundraising efficiency.

Denote the high-quality candidate as $H$ and the low-quality candidate as $L$, where $\eta_{H}>\eta_{L}$ and $H$ enjoys the initial voter disposition advantage.

Corollary to Result 1. In a contest for an open seat, if $\eta_{H}>\eta_{L}$ and $H$ has initial voter disposition advantage $\alpha \in\left(0, \frac{\eta_{L}}{\beta_{L}}\right)$, the probability of victory and the expected payoff of the high-quality candidate always improve due to the imposition of a binding campaign spending limit and/or making a

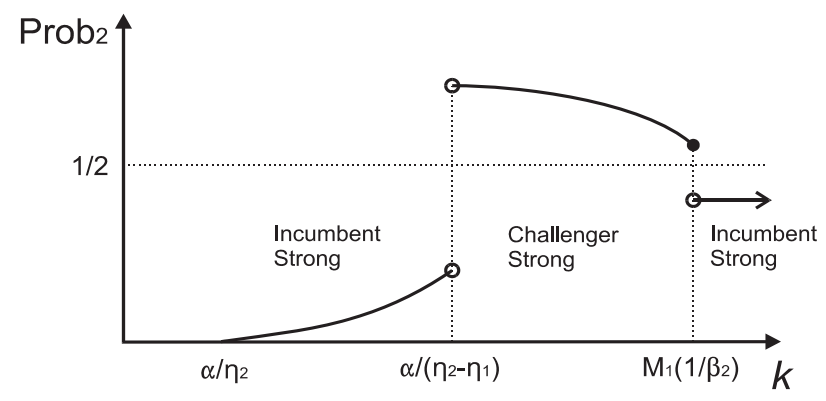

Fig. 5. Challenger's probability of victory. 
binding limit more restrictive, $\frac{\Delta \operatorname{Prob}_{H}}{\Delta k}<0$ and $\frac{\Delta E V_{H}}{\Delta k}<0$. Expected spending always decreases with a more restrictive cap, $\frac{\Delta E\left(a_{H}+a_{L}\right)}{\Delta k}>0$.

Proof. Follows directly from Result 1 where $H=1$ and $L=2$.

Since the high-quality candidate is more effective in campaign spending, one might think that a spending cap would hinder his ability to take full-advantage of his campaign spending efficiency. However, in equilibrium the cap is beneficial for the high-quality candidate. This result holds even if the high-quality candidate is less efficient in fundraising. His initial voter disposition advantage and superior campaign spending effectiveness allows the high-quality candidate to capture the strong position while the low-quality candidate has to spend more than the high-quality candidate to effectively match his score. With or without a spending cap, the supremum of the support of the low-quality candidate's equilibrium mixed strategy is higher than the supremum of the high-quality candidate's. Hence the imposition of a binding spending cap restricts the low-quality candidate while the high quality candidate is effectively not restricted. This leads to an increase in the win probability of the high-quality candidate. With a more restrictive cap the playing field is tilted in favor of the high-quality candidate and the low-quality candidate becomes less aggressive which, in turn, reduces the expected spending of the high-quality candidate, as well.

The above result is very promising for the welfare effects of campaign spending limits for open-seat contests. However the number of open-seat contests compared to the total number of contests is usually very small. Only about ten percent of US House contests from 1998 to 2004 were for an open seat. The figure was about $15 \%$ in the same time period for Canadian MP elections where spending limits were in place. ${ }^{20}$

Result 4. When a candidate has strictly positive expected payoff with a binding campaign spending cap, his marginal benefit to candidate quality decreases with a more restrictive cap as long as candidate quality improves effectiveness of campaign spending.

\section{Proof. Appendix.}

The intuition is straightforward. A candidate can make better use of his quality induced campaign effectiveness if he is allowed to spend more. In the bigger picture, this suggests that a more restrictive binding cap may make it less attractive for the political candidate to invest in quality building activities such as improving his expertise in history, economics, and philosophy or participating in public speech and leadership skill training seminars.

The political science literature points to some potentially positive effects of campaign spending limits on politician quality. If the campaign spending limit can level the playing field by reducing incumbency advantage, a challenger who is of higher quality than the incumbent can have a greater chance of victory. Also, in a dynamic context this may induce higher quality candidates to challenge the incumbent in the first place. ${ }^{21}$ This line of reasoning suggests that whenever spending limits reduce incumbency advantage they will increase candidate quality.

However the implication of Result 4 is that this is not necessarily the case. Result 4 identifies an additional channel for the effect of spending limits on candidate quality. As long as quality improves campaigning effectiveness, a more restrictive binding limit may give a smaller incentive to invest in quality and hence produce lower quality politicians.

\footnotetext{
${ }^{20}$ For US statistics see Duquette et al. (2008). For Canadian data see http://www. punditsguide.ca/files/Incumbency_Table1.html.

${ }^{21}$ Levitt and Wolfram (1997) show that incumbency advantage deters high-quality challengers.
}

\section{Discussion}

\subsection{Do limits help level the playing field?}

The main stated objective of political campaign spending limits is to level the playing field which is otherwise tilted in favor of the incumbent. Employing data on Canadian Federal elections, Milligan and Rekkas (2008) show that smaller limits lead to closer elections. This is encouraging. However our model suggests that transfer of policy recommendations from one political environment to the next may be problematic. The effect of a spending limit is likely to depend on the political institutional framework. In parliamentary systems with party discipline (such as in Canada, Brazil etc.) incumbents often do not enjoy the same degree of name recognition as US Senators, see Samuels (2001). Hence, the initial voter disposition advantage is likely to vary across political systems. While in Canada limits may help challengers, they might benefit incumbents in the US where incumbents typically enjoy a large initial voter disposition advantage (Results 2 and 3 combined).

\subsection{Do limits increase electoral prospects of small parties?}

A policy report by Phillips (2007) on strengthening democracy commissioned by former British Prime Minister Tony Blair suggests that "[l]owering the national expenditure limit for campaigning may help small and new parties to compete with the two principal established parties." The model may help shed some light to this discussion. If the larger party can be assumed to enjoy a head-start advantage in initial voter disposition, the smaller party may need to spend more in order to win the election. In contrast to the claim above, Results 1 and 2 suggest that a cap on campaign expenditure may in fact benefit the larger party rather than the smaller party. Furthermore Result 3 suggests that even if the existing cap benefits smaller parties, it does not necessarily follow that further lowering the limit will have the same effect.

\subsection{Do limits reduce the time and effort spent for fundraising?}

Running for elections is an expensive endeavor. The need to raise funds may take time away from other duties and raises the concern that legislative outcomes may be driven by money. If limits can help reduce expected campaign spending, they may help to improve the quality of democracy. Gross et al. (2002) find that in the U.S. from 1978 to 1997 in Gubernatorial elections, the existence of voluntary spending caps accompanied by public funding reduced the expected spending of both the incumbent and the challenger. Palda and Palda (1985) employ cross-sectional data from 95 constituencies of Ontario in the 1979 Canadian Federal Elections. The study finds that a \$1 increase in the limit lead to a $\$ 0.58$ increase in candidate expenditure.

While empirical evidence seems to be in favor of limits due to a reduction in campaign spending, the implications of the model call for caution. The effect of a limit on expected spending is shown to be nonmonotonic (Fig. 4) when the initial voter disposition advantage of the incumbent is mild. When the limit changes the identity of the strong candidate, the previously weak candidate can become more aggressive in his spending in a favorable playing field. ${ }^{22}$ Contrary to one of its intended consequences, the campaign spending limit legislation may yield increased effort for fundraising and open the door wider for monied interest's influence in policy making.

\footnotetext{
${ }^{22}$ Che and Gale (1998) and Pastine and Pastine (2010) have results on expected aggregate contributions with similar intuition for contribution caps.
} 


\section{Conclusion}

It is often feared that incumbency advantage degrades robust competition. When the playing field is not level, the incumbent may be less responsive to his constituents since he would have little reason to fear defeat; A higher quality challenger may have a lower probability of victory; The incumbent may be not challenged in the first place. Proponents of spending limits claim that limits can help level the playing field. However opponents suggest that the incumbents would not have legislated limits if limits did not benefit incumbents. This paper examines the effect of a spending limit on incumbency advantage in a contest where campaign spending serves as persuasive advertising. It also provides an analysis of the impact of spending limits on expected spending.

The arguments for and against spending limits are based on three sources of asymmetry between the incumbents and challengers; initial voter disposition advantage, fundraising efficiency, campaign spending effectiveness. When all three sources of asymmetry coexist, we find that the limit increases the challenger's probability of victory only when the following three conditions are jointly satisfied; the challenger is more effective in campaign spending, the incumbent has a mild initial voter disposition advantage and the limit is moderate. In all other cases the limit gives an additional tilt to the already uneven playing field in favor of the incumbent.

We also identify a new channel through which limits may affect candidate quality. If quality improves the effectiveness of campaign spending, a more restrictive binding limit on spending may lower the candidates' incentive to invest in quality.

Finally we show that spending limits may have the unintended consequence of increasing expected campaign spending. The limit can change the competitive balance giving the previously weak candidate an incentive to spend more aggressively. While out of the scope of this paper, it is often argued that increased campaign spending financed by campaign contributions may lead to greater policy influence of special interest groups.

\section{Acknowledgments}

We thank Todd Kaplan, an anonymous referee and participants at the 2011 Tournaments, Contests and Relative Performance Evaluation conference for helpful suggestions.

\section{Appendix A}

We consider cases where there is competition in equilibrium: $\alpha<\eta_{2} / \beta_{2}$ and $k>\alpha / \eta_{2}$. We omit the non-generic case where $k=$ $M_{i}(k) \leq \min \left(1 / \beta_{1}, 1 / \beta_{2}\right)$. Let $S$ and $W$ refer to the strong and weak candidates.

Claim 1. Candidate $W$ does not put a probability mass point on any level of spending greater than zero. Candidate $S$ does not put a probability mass point on any level of spending $a_{S} \in\left(0, M_{S}\left(\bar{a}_{W}\right)\right)$. There is no equilibrium in pure strategies.

Proof. Suppose that $W^{\prime}$ s lowest mass point in $\left(0, \bar{a}_{W}\right)$ is $a^{\prime} . M_{S}\left(a^{\prime}\right)>\bar{a}_{S}$ conflicts with the definition of the weak candidate. If $M_{S}\left(a^{\prime}\right)<\bar{a}_{S}$ or if $M_{S}\left(a^{\prime}\right)=\bar{a}_{S}$ and $k>1 / \beta_{S}$ then $S$ would not spend $M_{S}\left(a^{\prime}\right)$ or in the open interval below it as a slight increase in spending to just above $M_{S}\left(a^{\prime}\right)$ would result in a discrete increase in his probability of winning. Therefore $W$ could decrease spending slightly from $a^{\prime}$ with no decrease in his probability of winning.

The only remaining possibility is that $M_{S}\left(a^{\prime}\right)=\bar{a}_{S}=k$. If $a^{\prime}<\bar{a}_{W}<k$ then $M_{W}\left(\bar{a}_{S}\right)<\bar{a}_{W}$ a contradiction of the definition of $S$. Suppose that $a^{\prime}=\bar{a}_{W}=1 / \beta_{W}<k$. $S$ will put no mass in the open interval below $k$ as moving it up to $k$ results in a discrete increase in the probability of winning. If $S$ put no probability mass at $k$ then $W$ could reduce spending from $a^{\prime}$ with no loss. If $S$ did put mass at $k$ then $W$ would not win with certainty at $a^{\prime}=1 / \beta_{W}$ and so it would result in a negative expected payoff. $a^{\prime}=\bar{a}_{W}=k$ results in the non-generic case where $k=M_{i}(k)$ and is therefore omitted. The symmetric argument establishes that $S$ can have no mass point on $\bar{a} \in\left(0, M_{S}\left(\bar{a}_{W}\right)\right)$.

Candidate $W$ cannot have a mass point on any positive level of spending. If in a pure-strategy equilibrium $W$ had zero spending, $S^{\prime}$ s optimal response would be $a_{S^{\prime}}=\max \left(0, M_{S}(0)+\varepsilon\right)$. However in this case $W$ would prefer $M_{W}\left(a_{S^{\prime}}\right)+\varepsilon>0$. Both of these levels of spending are affordable and possible since $\alpha>\eta_{2} / \beta_{2}$ and $k>\alpha / \eta_{2}$. Hence there is no equilibrium in pure strategies.

Claim 2. Candidate 2 puts zero probability on $a_{2} \in\left(0, \alpha / \eta_{2}\right]$.

Proof. Zero spending wins with the same probability as $a_{2} \in\left(0, \alpha / \eta_{2}\right)$. Candidate 2 wins with $a_{2}=\alpha / \eta_{2}$ only if $a_{1}=0$. Either this chance is small enough that his expected value is negative, in which case he would prefer zero spending, or a slight increase in his spending would result in a discrete increase in his probability of winning.

Claim 3. Candidate $W$ has an infimum spending level of zero, $a_{W}^{\mathrm{inf}}=0$ and $E V_{W}=0$.

Proof. Suppose $a_{W}^{\mathrm{inf}}=0$. If $M_{S}\left(a_{W}^{\mathrm{inf}}\right)>0$ then Candidate 1 would never choose $a_{S} \in\left(0, M_{S}\left(a_{W}^{\inf }\right)\right)$ as $S$ would be putting in positive spending and would lose for sure since the probability of $W$ having spending of $a_{W}^{\text {inf }}$ is zero by Claim 1. Claim 1 also implies that the probability of $S$ choosing exactly $M_{S}\left(a_{W}^{\mathrm{inf}}\right)$ is zero, therefore $W$ could lower his spending without changing his probability of winning. If $M_{S}\left(a_{W}^{\mathrm{inf}}\right)<0$ then spending of zero would give $W$ the same probability of winning as the conjectured $a_{W}^{\mathrm{inf}}>0$, a contradiction. If $M_{S}\left(a_{W}^{\mathrm{inf}}\right)=0$ then $S=1$ and $a_{W}^{\mathrm{inf}}=\alpha / \eta_{2}$. By Claim 2 the probability of 2 having spending of $\alpha / \eta_{2}$ is zero. Hence if $a_{2}^{\text {inf }}=\alpha / \eta_{2}$ Candidate 2 is mixing in the open interval above $\alpha / \eta_{2}$. In this case 1 would put no probability at zero spending by the above argument and by Claim 1 Candidate 1 has no mass point on $(0, \varepsilon]$. Hence 2's probability of winning with spending of $M_{2}(\varepsilon)=\left(\alpha / \eta_{2}\right)^{+}$is approximately zero for small $\varepsilon$. So with spending $M_{2}(\varepsilon)$ Candidate 2 is putting in positive spending for a negligible probability of winning, hence $a_{2}^{\text {inf }} \neq \alpha / \eta_{2}$. $a_{2}^{\text {inf }} \in\left(0, \alpha / \eta_{2}\right)$ is not possible by Claim 2 so 2's infimum spending must be zero. So in all cases $a_{W}^{\text {inf }}=0$.

Zero is in the support of $W$ 's mixed strategy. If $W=2$ then he loses with certainty with that spending so $\mathrm{EV}_{W}=0$. If $W=1$ then, from the definition of $W, \bar{a}_{1}<M_{1}\left(\bar{a}_{2}\right)$, so 2 will not choose zero spending as he would lose for sure and he can guarantee victory and a positive payoff with spending of $M_{2}\left(\bar{a}_{1}\right)$. By Claim 2 there is zero probability of $a_{2} \in(0$, $\alpha / \eta_{2}$ ] so 1 has zero probability of winning with zero spending. Since $a_{W}^{\mathrm{inf}}=0$ and $W=1, \mathrm{EV}_{W}=0$.

Claim 4. Candidate $W$ has a supremum spending of $a_{W}^{\text {sup }}=\bar{a}_{W}$ while Candidate $S$ has a supremum spending of $a_{S}^{\text {sup }}=M_{S}\left(\bar{a}_{W}\right)$ and $E V_{S}=1$ $\beta_{S} M_{S}\left(\bar{a}_{W}\right) \geq 0$, with equality only if $a_{1}=M_{1}\left(\bar{a}_{2}\right)$.

Proof. $a_{W}^{\text {sup }}=0$ is not possible by Claim 1 . If $a_{W}^{\text {sup }} \in\left(0, \bar{a}_{W}\right)$ then $S$ would never set $a_{S}>\max \left(0, M_{S}\left(a_{W}^{\text {sup }}\right)\right)$ since $S$ can win for sure with that spending as the probability of $W$ choosing $a_{W}^{\text {sup }}$ is zero by Claim 1 . Therefore $W$ could win for sure with spending $a_{W}^{\text {sup }}+\varepsilon$ yielding a positive payoff for small enough $\varepsilon$, a contradiction of Claim 3. Likewise $a_{S}^{\text {sup }}<M_{S}\left(a_{W}^{\text {sup }}\right)$ allows candidate $W$ an opportunity to guarantee a positive payoff and hence contradicts Claim 3. Candidate $S$ can win for sure with spending of $M_{S}\left(a_{W}^{\text {sup }}\right)$ so $a_{S}^{\text {sup }}=M_{S}\left(\bar{a}_{W}\right)$ and $\mathrm{EV}_{S}=1-\beta_{S} M_{S}$ $\left(\bar{a}_{W}\right)$. By the definition of $\bar{a}_{S}$ this is strictly greater than zero whenever $\bar{a}_{S}>M_{S}\left(\bar{a}_{W}\right)$ and equal to zero if $\bar{a}_{S}=M_{S}\left(\bar{a}_{W}\right)$.

Claim 5. For Candidate 1 spending levels almost everywhere on $a_{1} \in(0$, $\left.a_{1}^{\text {sup }}\right)$ and for Candidate 2 spending levels almost everywhere on $a_{2} \in\left(\alpha / \eta_{2}, a_{2}^{\text {sup }}\right)$ must have positive probability. 
Proof. Suppose there were an interval $(t, v)$ in $\left(\alpha / \eta_{2}, a_{2}^{\text {sup }}\right)$ where Candidate 2 had zero probability of spending in $(t, v)$. Then 1 would have zero probability of spending on $\left(M_{1}(t), M_{1}(v)\right)$ since he could lower his spending to $M_{1}(t)$ and have the same chance of winning by Claim 2. But in this case 2 would never have spending of $v+\varepsilon$ as he could lower his spending to $t$, saving $v+\varepsilon-t$ in spending and losing only $F_{1}\left(M_{1}(v+\varepsilon)\right)-F_{1}\left(M_{1}(v)\right)$ in probability of winning. By Claim 1 this loss in probability is negligible for small $\varepsilon$. So if there were an interval of zero probability it must go all the way up to $a_{u}^{\text {sup }}$, which contradicts Claim 4. A symmetric argument rules out ranges of zero probability for Candidate 1 on $\left(0, a_{1}^{\text {sup }}\right)$.

Proof of Lemma 1. From Claim $4, a_{W}^{\text {sup }}=\bar{a}_{W}$ and $a_{S}^{\text {sup }}=M_{S}\left(\bar{a}_{W}\right)$. With any non-binding cap $\bar{a}_{W}=1 / \beta_{W}$ hence a non-binding cap requires $k>\max \left(1 / \beta_{W}, M_{S}\left(1 / \beta_{W}\right)\right) . S=2$ requires $\bar{a}_{1}<M_{1}\left(\bar{a}_{2}\right)$ which implies $M_{2}\left(\bar{a}_{1}\right)<\bar{a}_{2}$. So from Eq. (2), $M_{2}\left(1 / \beta_{1}\right)<1 / \beta_{2}$. Eq. (3) yields $\alpha<\frac{\eta_{2}}{\beta_{2}}-\frac{\eta_{1}}{\beta_{1}}$ which completes part (a). $S=1$ requires $\bar{a}_{1} \geq M_{1}\left(\bar{a}_{2}\right)$ so from Eq. (2), $1 / \beta_{1} \geq M_{1}\left(1 / \beta_{2}\right)$. Eq. (3) yields $\alpha \geq \frac{\eta_{2}}{\beta_{2}}-\frac{\eta_{1}}{\beta_{1}}$ which
completes part (b).

Proof of Lemma 2. From Claim 4, $a_{S}^{\text {sup }}=M_{S}\left(\bar{a}_{W}\right)$ and $a_{W}^{\text {sup }}=\bar{a}_{W}=$ $\min \left(1 / \beta_{W}, k\right)$. Suppose $a_{W}^{\text {sup }}=\bar{a}_{W}=k$, hence $a_{S}^{\text {sup }}=M_{S}(k)$. This must be less than $k$ by the definition of $S$. Thus for $S=2$ in equilibrium, $M_{2}(k)<k$ which yields $\left(\eta_{2}-\eta_{1}\right) k>\alpha$ which gives part (b). For $S=1$ in equilibrium $M_{1}(k)<k$, noting that we are not considering the nongeneric special case where $M_{1}(k)=k$, which yields $\left(\eta_{2}-\eta_{1}\right) k<\alpha$ which gives the result in part (a) as long as $k>1 / \beta_{W}$.

If $k>1 / \beta_{W}$ then for the cap to be binding $a_{S}^{\text {sup }}=M_{S}\left(1 / \beta_{W}\right)=$ $k \leq 1 / \beta_{S}$. From the definition of $S, \bar{a}_{S} \geq M_{S}\left(\bar{a}_{W}\right)$ with equality only if $S=1$. Hence the only possibility for a binding cap with $k>1 / \beta_{W}$ is $k=M_{1}\left(1 / \beta_{2}\right)$, in which case $\bar{a}_{1}=M_{1}\left(\bar{a}_{2}\right)$. Therefore $k=\left(\frac{\eta_{2}}{\beta_{2}}-\alpha\right) /$ $\eta_{1}>\frac{1}{\beta_{2}}$ which implies $\alpha<\left(\eta_{2}-\eta_{1}\right) \frac{1}{\beta_{2}}<\left(\eta_{2}-\eta_{1}\right) k$ which completes the proof of part (a).

Proof of Lemma 3. Without a binding cap, if $\frac{\eta_{2}}{\beta_{2}} \leq \frac{\eta_{1}}{\beta_{1}}$, then $(b)$ in Lemma 1 and Proposition 1 apply and $\operatorname{prob}_{1}=1-\frac{1}{2} \frac{\beta_{2} \beta_{1} \eta_{2}}{\eta_{1}}\left[\frac{1}{\beta_{2}^{2}}-\right.$ $\left.\left(\frac{\alpha}{\eta_{2}}\right)^{2}\right]$ since $\bar{a}_{2}=1 / \beta_{2}, \operatorname{prob}_{1}>1 / 2 \forall \alpha \in\left(0, \frac{\eta_{2}}{\beta_{2}}\right)$. If $\frac{\eta_{2}}{\beta_{2}}>\frac{\eta_{1}}{\beta_{1}}$, (a) in Lemma 1 and Proposition 2 apply when $\alpha \in\left[0, \frac{\eta_{2}}{\beta_{2}}-\frac{\eta_{1}}{\beta_{1}}\right)$ and $\operatorname{prob}_{1}=\frac{1}{2} \frac{\beta_{2} \eta_{1}}{\beta_{1} \eta_{2}}$ since $\bar{a}_{1}=1 / \beta_{1}, \operatorname{prob}_{1}<\frac{1}{2}$. Hence there is no incumbency advantage. When $\alpha \in\left[\frac{\eta_{2}}{\beta_{2}}-\frac{\eta_{1}}{\beta_{1}}, \frac{\eta_{2}}{\beta_{2}}\right)$, (b) in Lemma 1 and Proposition 1 apply and $\operatorname{prob}_{1}=1-\frac{1}{2} \frac{\beta_{2} \beta_{1} \eta_{2}}{\eta_{1}}\left[\frac{1}{\beta_{2}^{2}}-\left(\frac{\alpha}{\eta_{2}}\right)^{2}\right]$ since $\bar{a}_{2}=1 / \beta_{2}$. In this case, there is an incumbency advantage, $\operatorname{prob}_{1}>\frac{1}{2}$ if $\alpha \in\left(\left(\frac{\eta_{2}}{\beta_{2}}\left(\frac{\eta_{2}}{\beta_{2}}-\frac{\eta_{1}}{\beta_{1}}\right)\right)^{1 / 2}, \frac{\eta_{2}}{\beta_{2}}\right)$.

Proof of Proposition 1. Claims 2-5 demonstrate that in equilibrium 2 is indifferent among all spending levels almost everywhere on $\{0\} \cup\left(\alpha / \eta_{2}, \bar{a}_{2}\right]$ and 1 is indifferent among spending levels almost everywhere on $\left[0, M_{1}\left(\bar{a}_{2}\right)\right] . \mathrm{EV}_{2}=0$ by Claim 3. On $a_{2} \in\left(\alpha / \eta_{2}, \bar{a}_{2}\right)$ Candidate 2 wins with probability $F_{1}\left(M_{1}\left(a_{2}\right)\right)$ as there is zero probability that $a_{1}=M_{1}\left(a_{2}\right)$ by Claim 1 . So indifference of 2 in that range implies $F_{1}\left(M_{1}\left(a_{2}\right)\right)-\beta_{2} a_{2}=0$. This yields $F_{1}\left(a_{1}\right)=$ $\beta_{2}\left(\alpha+\eta_{1} a_{1}\right) / \eta_{2} \forall a_{1} \in\left[0, M_{1}\left(\bar{a}_{2}\right)\right]$. Hence 1 has a probability mass of $\alpha \beta_{2} / \eta_{2}$ at zero and a mass in the open interval above $M_{1}\left(\bar{a}_{2}\right)$ of $1-\beta_{2} \bar{a}_{2}$. Note that this mass is zero if the cap is not binding. $E V_{1}=1-\beta_{1} M_{1}\left(\bar{a}_{2}\right) \geq 0$ by Claim 4 . On $a_{1} \in\left(0, M_{1}\left(\bar{a}_{2}\right)\right)$ Candidate 1 wins with probability $F_{2}\left(M_{2}\left(a_{1}\right)\right)$ as there is zero probability that $a_{2}=M_{2}\left(a_{1}\right)$ by Claim 1 . So the indifference of 1 in that range implies $F_{2}\left(M_{2}\left(a_{1}\right)\right)-\beta_{1} a_{1}=1-\beta_{1} M_{1}\left(\bar{a}_{2}\right)$. This yields $F_{2}\left(a_{2}\right)=$ $1+\beta_{1} \eta_{2}\left(a_{2}-\bar{a}_{2}\right) / \eta_{1} \forall a_{2} \in\left(\alpha / \eta_{2}, \bar{a}_{2}\right] .2$ has a probability mass of $1-\beta_{1} \eta_{2} \bar{a}_{2} / \eta_{1}$ at zero spending. By Claim 2 Candidate 2 puts zero probability on $\left(0, \alpha / \eta_{2}\right)$.

Part (a) Expected value: Given by Claims 3 and 4. Part (b) Expected spending: On $a_{2} \in\left(\alpha / \eta_{2}, \bar{a}_{2}\right]$ the p.d.f. of 2's spending is $f_{2}\left(a_{2}\right)=$ $\beta_{1} \eta_{2} / \eta_{1}$. Hence his expected spending is $E\left(a_{2}\right)=\int_{a / \eta_{2}}^{\bar{a}_{2}} f_{2}(x) x d x$. On $a_{1} \in\left(0, M_{1}\left(\bar{a}_{2}\right)\right]$ the p.d.f. of 1 's spending is $f_{1}\left(a_{1}\right)=\beta_{2} \eta_{1} / \eta_{2}$ and 1 in the open interval above $M_{1}\left(\bar{a}_{2}\right)$. Hence his expected spending is $E\left(a_{1}\right)=\int_{0}^{M_{1}\left(\bar{a}_{2}\right)} f_{1}(x) x d x+\left[1-F_{1}\left(M_{1}\left(\bar{a}_{2}\right)\right)\right] M_{1}\left(\bar{a}_{2}\right)$. Part (c) Probability Candidate 2 wins: In equilibrium there is zero probability of ties where $a_{2}=M_{1}\left(a_{2}\right)$ by Claim 1 so the probability that 2 wins is given by $\operatorname{prob}_{2}=\int_{a / \eta_{2}}^{\bar{a}_{2}} F_{1}\left(M_{1}(x)\right) f_{2}(x) d x$.

Proof of Proposition 2. Claims 2-5 demonstrate that in equilibrium 2 is indifferent among all spending levels almost everywhere on $\left(a / \eta_{2}\right.$, $\left.M_{2}\left(\bar{a}_{1}\right)\right]$ and 1 is indifferent among spending levels almost everywhere on $\left[0, \bar{a}_{1}\right] . E V_{1}=0$ by Claim 3 . On $a_{1} \in\left[0, \bar{a}_{1}\right)$ Candidate 1 wins with probability $F_{2}\left(M_{2}\left(a_{1}\right)\right)$ as there is zero probability that $a_{2}=M_{2}\left(a_{1}\right)$ by Claim 1 . So indifference of 1 in that range implies $F_{2}\left(M_{2}\left(a_{1}\right)\right)-\beta_{1} a_{1}=0$. This yields $F_{2}\left(a_{2}\right)=\beta_{1}\left(\eta_{2} a_{2}-\alpha\right) /$ $\eta_{1} \forall a_{2} \in\left(\alpha / \eta_{2}, M_{2}\left(\bar{a}_{1}\right)\right]$. Hence 2 has no probability on $\left[0, \alpha / \eta_{2}\right]$ and a probability mass in the open interval above $M_{s}\left(\bar{a}_{1}\right)$ of $1-\beta_{1} \bar{a}_{1}$. Note that this mass is zero if the cap is not binding. $\mathrm{EV}_{2}=1-\beta_{2} M_{2}\left(\bar{a}_{1}\right) \geq 0$ by Claim 4 . On $a_{2} \in\left(\alpha / \eta_{2}, M_{2}\left(\bar{a}_{1}\right)\right)$ Candidate 2 wins with probability $F_{1}\left(M_{1}\left(a_{2}\right)\right)$ as there is zero probability that $a_{1}=M_{1}\left(a_{2}\right)$ by Claim 1 . So the indifference of 2 in that range implies $F_{1}\left(M_{1}\left(a_{2}\right)\right)-\beta_{2} a_{2}=1-$ $\beta_{2} M_{2}\left(\bar{a}_{1}\right)$. This yields $F_{1}\left(a_{1}\right)=1+\frac{\beta_{2} \eta_{1}}{\eta_{2}}\left(a_{1}-\bar{a}_{1}\right) \forall a_{1} \in\left[0, \bar{a}_{1}\right] .1$ has a probability mass of $1-\beta_{2} \eta_{1} \bar{a}_{1} / \eta_{2}$ at zero spending.

Part (a) Expected value: Given by Claims 3 and 4. Part (b) Expected spending: On $a_{2} \in\left(a / \eta_{2}, M_{2}\left(\bar{a}_{1}\right)\right]$ the p.d.f. of 2's spending is $f_{2}\left(a_{2}\right)=$ $\beta_{1} \eta_{2} / \eta_{1}$ and he has a probability mass in the open interval above $M_{2}\left(\bar{a}_{1}\right)$. Hence his expected spending is $E\left(a_{2}\right)=\int_{\alpha / \eta_{2}}^{M_{2}\left(\bar{a}_{1}\right)} f_{2}(x) x d x+$ $\left[1-\mathrm{F}_{2}\left(M_{2}\left(\bar{a}_{1}\right)\right)\right] M_{2}\left(\bar{a}_{1}\right)$. On $a_{1} \in\left(0, \bar{a}_{1}\right]$ the p.d.f. of 1 's spending is $f_{1}\left(a_{f}\right)=\beta_{2} \eta_{1} / \eta_{2}$. Hence his expected spending is $E\left(a_{1}\right)=\int_{0}^{a_{1}} f_{1}(x) x d x$. Part (c) Probability that Candidate 2 wins: In equilibrium there is zero probability of ties where $a_{2}=M_{1}\left(a_{2}\right)$ by Claim 1 so the probability that 2 wins is given by $\operatorname{prob}_{2}=1-\int_{0}^{a_{1}} F_{2}\left(M_{2}(x)\right) f_{1}(x) d x$.

Proof of Result 1. Since $\eta_{2} \leq \eta_{1}$, by Lemma 2 with a binding cap Proposition 1 applies and hence $\frac{\partial \mathrm{EV}_{1}}{\partial k}=\frac{-\beta_{1} \eta_{2}}{\eta_{1}}<0$ and $\frac{\partial \operatorname{prob}_{2}}{\partial k}=$ $\frac{\beta_{1} \beta_{2} \eta_{2} k}{\eta_{1}}>0$. By Lemma 1, if $\alpha \in\left[\frac{\eta_{2}}{\beta_{2}}-\frac{\eta_{1}}{\beta_{1}}, \frac{\eta_{2}}{\beta_{2}}\right)$ then Proposition 1

applies without a cap as well and hence Proposition 1's subsections also yield the result for the initial imposition of the cap.

If $\alpha<\frac{\eta_{2}}{\beta_{2}}-\frac{\eta_{1}}{\beta_{1}}$, which can occur if the challenger has a fundraising advantage, then by Lemma 1 without a cap Proposition 2 applies and hence the imposition of a cap switches the equilibrium from Proposition 2 to Proposition 1. Nevertheless, from the subsections of the propositions, without a cap $\mathrm{EV}_{1}=0$ while with a binding cap $E V_{1} \geq 0$. Without a binding cap $\bar{a}_{1}=1 / \beta_{1}$ and hence $\operatorname{prob}_{1}=\frac{1}{2} \frac{\beta_{2} \eta_{1}}{\eta_{2} \beta_{1}}$

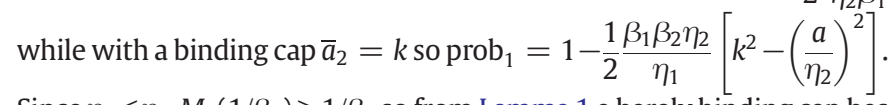
Since $\eta_{2} \leq \eta_{1}, M_{2}\left(1 / \beta_{1}\right) \geq 1 / \beta_{1}$ so from Lemma 1 a barely binding cap has $k=M_{2}\left(1 / \beta_{1}\right)$. From that and the fact that $\alpha<\frac{\eta_{2}}{\beta_{2}}-\frac{\eta_{1}}{\beta_{1}}$ the incumbent's probability of victory is higher with a barely binding cap than with no cap on campaign spending.

Proof of Result 2. Since $\beta_{1}<\beta_{2}, \frac{\eta_{2}-\eta_{1}}{\beta_{2}}>\frac{\eta_{2}}{\beta_{2}}-\frac{\eta_{1}}{\beta_{1}}$ so $M_{1}\left(1 / \beta_{2}\right)<$ $1 / \beta_{2}$. From Lemma 1 part (b) a binding cap has $k \leq 1 / \beta_{2}$. Hence for any 
binding cap $\alpha>\left(\eta_{2}-\eta_{1}\right) k$ so Lemma 2 implies that Proposition 1 applies. In the absence of a binding cap $\bar{a}_{1}=1 / \beta_{1}$ and $\bar{a}_{2}=1 / \beta_{2}$. Therefore $\alpha>\frac{\eta_{2}}{\beta_{2}}-\frac{\eta_{1}}{\beta_{1}}$ implies $\bar{a}_{1}>M_{1}\left(\bar{a}_{2}\right)$ and hence Proposition 1 applies without a cap as well. The subsections of Proposition 1 yield the results.

Proof of Result 3. In the absence of a binding cap $\bar{a}_{1}=1 / \beta_{1}$ and $\bar{a}_{2}=1 / \beta_{2}$. Therefore $\alpha \geq \frac{\eta_{2}}{\beta_{2}}-\frac{\eta_{1}}{\beta_{1}}$ implies $\bar{a}_{1} \geq M_{1}\left(\bar{a}_{2}\right)$ and hence Proposition 1 applies without a cap.

(a) The introduction of a barely binding limit. From Lemma 1 part (b) a barely binding cap has $k=\max \left(1 / \beta_{2}, M_{1}\left(1 / \beta_{2}\right)\right)$. Since $\alpha<\left(\eta_{2}-\eta_{1}\right) / \beta_{2}$, $k=M_{1}\left(1 / \beta_{2}\right)=\left(\frac{\eta_{2}}{\beta_{2}}-a\right) / \eta_{1}$. Therefore $\bar{a}_{1}=k, \bar{a}_{2}=1 / \beta_{2}$ and $\bar{a}_{1}<M_{1}\left(\bar{a}_{2}\right)$ so with a barely binding cap Proposition 2 applies. Plugging these values into the results in the subsections of Propositions 1 and 2 and noting that $\alpha>\frac{\eta_{2}}{\beta_{2}}-\frac{\eta_{1}}{\beta_{1}}$ proves that the introduction of a barely binding limit leads to a jump down in the probability that the incumbent wins and a jump up in the expected total campaign spending.

(b) Making a moderate limit, $k \in\left(\frac{a}{\eta_{2}-\eta_{1}}, \frac{1}{\eta_{1}}\left(\frac{\eta_{2}}{\beta_{2}}-\alpha\right)\right)$, more restrictive. From the proof of part (a) and Lemma 2 in this range of $k$ Proposition 2 applies so its subsections and noting that $\bar{a}_{1}=k$, establishes that in this range of $k$, making the limit more restrictive decreases the probability that the incumbent wins and decreases expected total spending.

(c) Reducing the limit from $\left(\frac{\alpha}{\eta_{2}-\eta_{1}}\right)^{+}$to $\left(\frac{\alpha}{\eta_{2}-\eta_{1}}\right)^{-}$. From the proof of part (a) and the fact that $\alpha<\left(\eta_{2}-\eta_{1}\right) / \beta_{2}$ the cap is binding for $k=\left(\frac{\alpha}{\eta_{2}-\eta_{1}}\right)^{+}$. From Lemma 2 when $k>\alpha /\left(\eta_{2}-\eta_{1}\right)$ Proposition 2 applies and $\bar{a}_{1}=k$ while when $k<\alpha /\left(\eta_{2}-\eta_{1}\right)$ Proposition 1 applies and $\bar{a}_{2}=k$. Taking left limit of the results in the subsections of Proposition 2 and the right limit of the results in the subsections of Proposition 1 as $k \rightarrow \alpha /\left(\eta_{2}-\eta_{1}\right)$ and noting that $\alpha<\left(\eta_{2}-\eta_{1}\right) / \beta_{2}$ and $\beta_{1}<\beta_{2}$ establishes that reducing the limit from $\left(\frac{\alpha}{\eta_{2}-\eta_{1}}\right)^{+}$to $\left(\frac{\alpha}{\eta_{2}-\eta_{1}}\right)^{-}$leads to an increase in the probability that the incumbent wins and leads to an increase in the incumbent's $k<\left(\frac{\alpha}{\eta_{2}-\eta_{1}}\right)$, Proposition 1 applies so its subsections show that further decreases in $k$ will benefit the incumbent.

Proof of Result 4. With a binding cap in Proposition $1 \bar{a}_{1}=k, \bar{a}_{2}=$ $\left(\eta_{2} k-\alpha\right) / \eta_{1}<k, E V_{1}>0, E V_{2}=0$. In that case $\frac{\partial^{2} E V_{1}}{\partial \eta_{1} \partial k}=\beta_{1} \eta_{2} /$ $\eta_{1}^{2}>0$. With a binding cap in Proposition $2 \bar{a}_{1}=k, \bar{a}_{2}=\left(\eta_{1} k+\alpha\right) /$ $\eta_{2}<k, E V_{1}=0, E V_{2}>0$. In that case $\frac{\partial^{2} E V_{2}}{\partial \eta_{2} \partial k}=\beta_{2} \eta_{1} / \eta_{2}^{2}>0$. So the result holds directly as long as the reduction in $k$ does not switch the equilibrium from one proposition to the other. From Lemma 2 the only time this happens is when $\eta_{2}>\eta_{1}$ and $k$ drops from $\alpha /\left(\eta_{2}>\eta_{1}\right)^{+}$to $\alpha /\left(\eta_{2}>\eta_{1}\right)^{-}$and the equilibrium switches from Proposition 2 to Proposition 1 and $\frac{\partial E V_{2}}{\partial \eta_{2}}$ falls from $\frac{\beta_{2}}{\eta_{2}^{2}}\left(\eta_{1} k+\alpha\right)>0$ to zero.

\section{References}

Abrajano, M. and Morton, R., 2004. All style and no substance? The strategic calculus of campaign advertising. Unpublished results.

Abramowitz, A., 1988. Explaining senate election outcomes. American Political Science Review 82, 385-403.

Austen-Smith, D., 1987. Interest groups, campaign contributions, and probabilistic voting. Public Choice 54, 123-139.

Becker, G., Murphy, K., 1993. A simple theory of advertising as a good or bad. Quarterly Journal of Economics 108, 1109-1116.

Bender, B., 1988. An analysis of congressional voting on legislation limiting congressional campaign expenditures. Journal of Political Economy 96 (5) 1005-1021.
Butters, G., 1977. Equilibrium distributions of sales and advertising prices. Review of Economic Studies 44 (3), 465-491.

Che, Y., Gale, I., 1998. Caps on political lobbying. American Economic Review 88 (3), 643-651.

Coate, S., 2004. Political competition with campaign contributions and informative advertising. Journal of the European Economic Association 2 (5), $772-804$.

Dixit, A., Norman, V., 1978. Advertising and welfare. Bell Journal of Economics 9, $1-17$.

Duquette, C., Caudill, S., Mixon, F., 2008. The impact of money on elections: evidence from open seat races in the United States House of Representatives, 1990-2004. Economics Bulletin 4 (2), 1-12.

Erikson, R., Palfrey, T., 1998. Campaign spending and incumbency: an alternative simultaneous equations approach. Journal of Politics 60 (2), 355-373.

Evens, T., 2007. An empirical test of why incumbents adopt campaign spending limits. Public Choice 132 (3-4), 437-456.

Gelman, A., King, G., 1990. Estimating incumbency advantage without bias. American Journal of Political Science 34, 1142-1164 November.

Glantz, S., Abramowitz, A., Burkart, M., 1976. Election outcomes: whose money matter. Journal of Politics 38, 1033-1038.

Green, D., Krasno, J., 1988. Salvation for the spendthrift incumbent: reestimating the effects of campaign spending in House elections. American Journal of Political Science 32 (4), 884-907.

Green, D., Krasno, J., 1990. Rebuttal to Jacobson's 'New evidence for old arguments.'. American Journal of Political Science 34 (2), 363-372.

Gross, D., Goidel, R., Shields, T., 2002. State campaign finance regulations and electoral competition. American Politics Research 30 (2), 143-165.

Grossman, G., Helpman, E., 1996. Electoral competition and special interest politics. Review of Economic Studies 63, 265-286.

Hall, R., Wayman, F., 1990. Buying time: moneyed interests and the mobilization of bias in congressional committees. American Political Science Review 3, 797-820.

Jacobson, G., 1978. The effects of campaign spending in congressional elections. American Political Science Review 72 (2), 469-491.

Jacobson, G., 1981. Incumbents' advantages in the 1978 US congressional elections. Legislative Studies Quarterly 6 (2), 183-200.

Jacobson, G., 1985. Money and votes reconsidered: congressional elections, 1972-1982. Public Choice 47 (1), 7-62.

Jacobson, G., 1990. The effects of campaign spending in House elections: new evidence for old arguments. American Journal of Political Science 34 (2), 334-362.

Jamie, C., Engstrom, E., Roberts, J., 2007. Candidate quality, the personal vote, and incumbency advantage in congress. American Political Science Review 101 (2), 290-301.

Kahn, K., Kenney, P., 1999. The Spectacle of US Senate Campaigns. Princeton University Press, Princeton.

Kirkegaard, R., 2010. Preferential treatment may hurt: another application of the allpay auction. Unpublished results.

Konrad, K., 2002. Investment in the absence of property rights: the role of incumbency advantages. European Economic Review 46, 1521-1537.

Konrad, K., 2004. Inverse campaigning. Economic Journal 114, 69-82.

Levitt, S., 1994. Using repeat challengers to estimate the effect of campaign spending on election outcomes in the U.S. House. Journal of Political Economy 41, 777-798.

Levitt, S., Wolfram, C., 1997. Decomposing the sources of incumbency advantage in the US House of Representatives. Legislative Studies Quarterly 22 (1), $45-60$.

Meirowitz, A., 2008. Electoral contests, incumbency advantages and campaign finance. Journal of Politics 70 (3), 681-699.

Milligan, K., Rekkas, M., 2008. Campaign spending limits, incumbent spending, and election outcomes. Canadian Journal of Economics 41 (4), 1351-1374.

Mueller, D., Stratmann, T., 1994. Informative and persuasive campaigning. Public Choice $81(1 / 2), 55-77$.

Palda, F., 1992. The determinants of campaign spending: the role of the government jackpot. Economic Inquiry 30, 627-638.

Palda, F., Palda, K., 1985. Ceilings on campaign spending: hypothesis and partial test with Canadian data. Public Choice 45, 313-331.

Pastine, I., Pastine, T., 2002. Consumption externalities, coordination and advertising. International Economic Review 43 (3), 919-943.

Pastine, I., Pastine, T., 2010. Politician preferences, law-abiding lobbyists and caps on political contributions. Public Choice 145 (1-2), 81-101.

Pastine and Pastine, 2011. All-pay contests with constraints. Unpublished results.

Phillips, H., 2007. Strengthening democracy: fair and sustainable funding of political parties. The Stationary Office Limited on Behalf of the Controller of her Majesty's Stationary Office, ID. 5538142, London.

Potters, J., Sloof, R., van Winden, F., 1997. Campaign expenditures, contributions and direct endorsements: the strategic use of information and money to influence voter behavior. European Journal of Political Economy 13, 1-13.

Prat, A., 2002a. Campaign advertising and voter welfare. Review of Economic Studies 69 (4), 999-1017.

Prat, A. 2002b. Campaign spending with office-seeking politicians, rational voters, and multiple lobbies. Journal of Economic Theory 103 (1), 162-189.

Sahuguet, N., Perisco, N., 2006. Campaign spending regulation in a model of redistributive politics. Economic Theory 28 (1), 95-124.

Samuels, D., 2001. Incumbents and challengers on a level playing field: assessing the impact of campaign finance in Brazil. Journal of Politics 63 (2), 569-584.

Seymour, C., 1970. Electoral Reform in England and Wales. David \& Charles Reprints, Devon.

Siegel, R., 2010. Head starts in all-pay contests. Unpublished results. 
Soberman, D., Sadoulet, L., 2007. Campaign spending limits and political advertising. Management Science 53 (10), 1521-1532.

Tullock, G., 1980. Efficient rent seeking. In: Buchanan, J., Tollison, R., Tullock, G. (Eds.), Toward a Theory of the Rent-seeking Society. Texas A \& M University Press, College Station, pp. 97-112.
Walecki, M., 2007. Spending limits as a policy option. IFES Political Finance White Paper Series. June.

Welch, W., 1981. Money and votes: a simultaneous equation model. Public Choice 36 (2), 209-234 